\title{
REVIEWS
}

\section{Targeting Bruton's tyrosine kinase in B cell malignancies}

\section{Rudi W. Hendriks, Saravanan Yuvaraj and Laurens P. Kil}

Abstract | Bruton's tyrosine kinase (BTK) is a key component of $B$ cell receptor (BCR) signalling and functions as an important regulator of cell proliferation and cell survival in various $B$ cell malignancies. Small-molecule inhibitors of BTK have shown antitumour activity in animal models and, recently, in clinical studies. High response rates were reported in patients with chronic lymphocytic leukaemia and mantle cell lymphoma. Remarkably, BTK inhibitors have molecular effects that cannot be explained by the classic role of BTK in BCR signalling. In this Review, we highlight the importance of BTK in various signalling pathways in the context of its therapeutic inhibition.

\section{B cell receptor (BCR). An antigen receptor that is specifically expressed on the cell surface of B cells and composed of two immunoglobulin heavy $(\mathrm{lgH})$ chains and two immunoglobulin light (IgL) chains.}

\section{Pre-BCR}

A receptor that consists of an immunoglobulin heavy (IgH) chain, which is associated with two germline-encoded surrogate light chain

components and is transiently expressed on the cell surface of pre-B cells after successful IgH chain rearrangement.
Department of Pulmonary Medicine, Room Ee2251a, Erasmus MC Rotterdam, PO Box 2040, NL 3000 CA Rotterdam, the Netherlands. Correspondence to R.W.H. e-mail: r.hendriks@erasmusmc.nl doi:10.1038/nrc3702
Bruton's tyrosine kinase (BTK) was originally identified in 1993 as a non-receptor protein tyrosine kinase that is defective in the inherited immunodeficiency disease $\mathrm{X}$-linked agammaglobulinaemia ${ }^{1-3}$ (XLA). In affected males, B lymphocytes and immunoglobulins are almost completely absent from the circulation owing to a severe defect in B cell development (BOX 1). This defect was shown to be intrinsic to the $B$ cell lineage: in female carriers of this disease, the $\mathrm{X}$ chromosome with the mutant $B T K$ gene is inactivated in the $B$ cell lineage, which suggests that B-lineage cells that harbour a defective BTK allele on the active $\mathrm{X}$ chromosome have a selective disadvantage ${ }^{4}$. Patients with XLA have no significant developmental defects in other immune cells, and this is consistent with the restriction of clinical features to B cell immunity. Likewise, in the CBA/N strain of mice, the less severe X-linked immunodeficiency (XID) phenotype was found to be due to a point mutation in $B t k^{5,6}$, and the effects of this mutation also seem to be limited to the $\mathrm{B}$ cell population (BOX 1).

Shortly after the discovery of BTK, it was shown that stimulation of the B cell receptor (BCR) in mature B cells induces tyrosine phosphorylation of BTK and increases its kinase activity, thereby placing BTK in the BCR signal transduction pathway ${ }^{7-9}$. This is consistent with the defective activation that is observed in BCR-stimulated Btk-deficient mouse B cells, which lack progression into cell division, have a high susceptibility to apoptosis and have a limited induction of activation markers on their cell surface ${ }^{10-12}$. Moreover, the XLA phenotype in humans can be explained by a parallel function of $\mathrm{BTK}$ in signalling downstream of the pre-BCR. The pre$\mathrm{BCR}$ is an immature form of the BCR that monitors for functional immunoglobulin heavy $(\operatorname{IgH})$ chain rearrangement by deposition of the IgH $\mu$ protein on the cell surface, thereby providing signals for survival, proliferation and cellular differentiation ${ }^{13}$. Loss of BTK function disrupts this pre-BCR checkpoint function; therefore, in patients with XLA, clonal expansion and developmental progression of IgH $\mu$ chain-expressing pre-B cells is abrogated (BOX 1).

BTK is expressed in many B cell leukaemias and lymphomas $^{14,15}$. Because of this, targeting BTK to develop new treatment modalities for B cell malignancies became an attractive idea. In 1999, only a few years after the identification of BTK, the first rationally designed BTK small-molecule inhibitor (LFM-A13) was shown to have anti-leukaemic activity in vitro ${ }^{16}$ (TABLE 1). More selective BTK inhibitors were subsequently developed, including the irreversible inhibitor ibrutinib (also known as PCI-32765) (TABLE 1), which induced objective clinical responses in dogs with spontaneous B cell non-Hodgkin's lymphoma ${ }^{17}$. Ibrutinib was also used to show that BTK is involved in oncogenic BCR signalling that controls the survival of a human activated B cell-like subtype of diffuse large B cell lymphoma ${ }^{18}$ (ABC-DLBCL). Ibrutinib monotherapy has recently shown encouraging clinical activity in patients with chronic lymphocytic leukaemia (CLL) and mantle cell lymphoma (MCL) in Phase II trials ${ }^{19,20}$. As a result, ibrutinib received breakthrough designation and was approved for the treatment of relapsed MCL by the US Food and Drug Administration (FDA) in 2013.

Because of the XLA and XID phenotypes and the central role of the pre-BCR and the BCR in B cell development and function, BTK is most intensely studied in the context of pre-BCR and BCR signalling. 


Key points
- Bruton's tyrosine kinase (BTK) was originally identified as a non-receptor protein
tyrosine kinase that is defective in the inherited immunodeficiency disease X-linked
agammaglobulinaemia (XLA).
- BTK has long been known to be a key component of B cell receptor (BCR) signalling
that regulates B cell proliferation and survival.
- Recently, a small-molecule inhibitor of BTK, called ibrutinib, has shown antitumour
activity in patients with various B cell malignancies.
- The antitumour activity of BTK inhibition is not solely dependent on the role of BTK in
BCR signalling.
- BTK inhibition also targets Toll-like receptor (TLR) signalling, B cell adhesion and
migration, as well as cells in the tumour microenvironment.
- Ibrutinib-induced lymphocytosis in patients with chronic lymphocytic leukaemia and
mantle cell lymphoma leads to the effective expulsion of malignant B cells out of their
nursing microenvironment.
- For many different B cell malignancies, treatment with BTK inhibitors is expected to
be more effective and have fewer toxic effects than currently used therapies.

Diffuse large B cell lymphoma (DLBCL). Numerous heterogeneous subtypes of mostly aggressive B cell lymphomas. The gene expression signatures of activated B cell-like DLBCL (ABC-DLBCL) and germinal centre-like DLBCL (GC-DLBCL) resemble those of activated peripheral blood $B$ cells and germinal centre B cells, respectively.

Chronic lymphocytic leukaemia

(CLL). A leukaemia that mostly affects the elderly and that is characterized by a lymphocytosis ( $>5 \times 10^{9}$ $B$ cells per litre) of monoclonal $\mathrm{CD} 5+\mathrm{B}$ cells.

Mantle cell lymphoma (MCL). An aggressive form of non-Hodgkin's lymphoma that is characterized by cell cycle deregulation because of cyclin D1 overexpression, which is translocated as part of the $t(11 ; 14)$ translocation. Additional aberrations in genes that control the cell cycle and DNA damage responses have been reported.

Toll-like receptors (TLRS). Innate receptors that are present on the cell surface or in endosomes and that recognize distinct, highly conserved molecular motifs, including polysaccharides, DNA and RNA, that are shared by pathogens.
However, BTK is also involved in signalling pathways downstream of many other receptors, including G protein-coupled chemokine receptors and Toll-like receptors (TLRs). Moreover, despite the apparently B cellrestricted phenotype in XLA and XID, BTK is expressed in all haematopoietic cells, except in T lymphocytes ${ }^{14,21}$. Intriguingly, in vitro studies, preclinical investigations in animal models and clinical trials have now provided good evidence that the antitumour activity of BTK inhibitors is not solely dependent on the role of BTK in BCR signalling. Rather, BTK inhibition also targets TLR signalling, B cell adhesion and migration, and cells in the tumour microenvironment.

In this Review, we highlight the importance of BTK in multiple signalling pathways in B lymphocytes and other haematopoietic cells. We also discuss the crucial role of BTK in oncogenic signalling that is essential for the survival of leukaemic B cells. In addition, we discuss the promising results of recent clinical trials indicating that although resistance may develop in some cases, for many different B cell malignancies, treatment with BTK inhibitors is expected to be more effective and have fewer toxic effects than currently used therapies.

\section{BTK structure, activity and regulation}

Together with four other members (BOX 2), BTK belongs to the TEC family of non-receptor kinases, which have been strongly conserved throughout evolution ${ }^{22}$. The domain structure of BTK is similar to that of the SRC family kinases, and it contains the SRC homology domains (SH domains) $\mathrm{SH} 2$ and $\mathrm{SH} 3$, as well as a catalytic domain (FIG. 1). However, unlike SRC family kinases, BTK has an amino-terminal pleckstrin homology domain (PH domain) and a proline-rich TEC homology $(\mathrm{TH})$ domain, which contains a zinc-finger motif that is important for optimal activity and stability of the protein ${ }^{22,23}$. SRC family kinases are constitutively membrane-associated owing to myristoylation, whereas BTK is cytoplasmic and only transiently recruited to the membrane. This requires binding of the BTK PH domain to phosphatidylinositol-3,4,5-trisphosphate (PIP3), which is generated by PI3K.
BTK activation is initiated by cell membrane association and phosphorylation of Y551 in the kinase domain, either by a SRC family kinase or by spleen tyrosine kinase (SYK). This promotes the catalytic activity of BTK and results in its autophosphorylation at position Y223 in the SH3 domain ${ }^{24,25}$. Autophosphorylation is increased in the $\mathrm{E} 41 \mathrm{~K}$ gain-of-function mutation in the $\mathrm{PH}$ domain, and expression of this mutant can transform fibroblasts ${ }^{26}$. However, transgenic expression of BTK-E41K showed that this mutant does not have oncogenic activity in B cells or myeloid cells in vivo ${ }^{27}$, and no constitutively active BTK mutants have been identified in malignancies to date.

Almost 700 unique loss-of-function BTK mutations have currently been described in the BTKbase mutation registry for $\mathrm{XLA}^{28}$. These include missense, nonsense and splice site mutations, as well as deletions and insertions, and these alterations are more or less equally distributed over the gene. However, missense mutations or in-frame deletions are absent in the $\mathrm{SH} 3$ domain - although, based on its size, 25 of the 251 mutations of this type identified so far should be located in this domain. Therefore, the SH3 domain is either not crucial for BTK function or it has a regulatory role. In particular, the functional importance of SH3 Y223 autophosphorylation remains unclear because phosphorylation of Y223 does not seem to affect BTK activity, and the transgenic expression of BTK-Y223F essentially corrected the XID phenotype ${ }^{29}$.

Although predominantly cytoplasmic, a small proportion of BTK is detected in the nucleus ${ }^{30}$. It has been proposed that BTK functions as a transcriptional regulator in $\mathrm{B}$ cells by interacting with various nuclear proteins, including BRIGHT (also known as ARID3A) and BAM11 (encoded by MLLT1) (FIG. 1), in a nuclear complex that regulates the transcription factor TFII- ${ }^{31,32}$. However, the importance of nuclear BTK activity remains elusive.

Upon BCR stimulation, mature B cells increase BTK levels ${ }^{33}$, but the post-transcriptional mechanisms involved are complex and only partially resolved. These include regulation of BTK expression by microRNA-185 $(\mathrm{miR}-185)^{34}$, as well as a proteasome-dependent positive autoregulatory feedback loop by which BTK stimulates transcription from its own promoter through a pathway involving nuclear factor- $\kappa \mathrm{B}(\mathrm{NF}-\kappa \mathrm{B})^{35}$. Studies in mice have shown that precise regulation of BTK expression levels is essential for normal B cell function. The expression of subphysiological levels of transgenic Btk only partially corrects the phenotype of Btk-deficient $\mathrm{B}$ cells, whereas physiological levels provide a complete rescue $^{36,37}$. Moreover, transgenic overexpression of wildtype human BTK in mice results in reduced susceptibility to apoptosis and an autoimmune pathology ${ }^{38}$. Although the overexpression of BTK in B cells did not induce neoplasia in transgenic mice, it did accelerate disease onset and increase mortality in a CLL mouse model ${ }^{39}$.

This complex regulation of BTK function by membrane association, the induction of enzymatic activity and the modulation of protein expression levels is best studied in the context of BCR signalling, as discussed below. 
SRC family kinases

SRC kinase, together with other members of the SRC kinase

family, is a crucial regulator of cellular proliferation, survival and migration that is frequently activated in different types of cancers.

SRC homology domains (SH domains). The SH domains $\mathrm{SH} 2$ and $\mathrm{SH} 3$ are protein modules that are involved in protein-protein interaction and that bind to phosphorylated tyrosines and proline-rich regions, respectively.

Pleckstrin homology domain

(PH domain). PH domains are protein modules that can bind to phosphatidylinositol lipids and that are involved in the recruitment of proteins to membranes - in particular, the cell membrane.

Wiskott-Aldrich syndrome protein

(WASP). The WASP protein is a cytoplasmic protein that is defective in the X-linked immunodeficiency Wiskott-Aldrich syndrome. It functions as an actin regulator by binding to and activating the ARP2-ARP3 complex.

\section{BTK and BCR signalling}

Activation of BTK by BCR signalling. The BCR complex is non-covalently associated with a disulphide-linked Ig $\alpha$ (also known as CD79A)- $\operatorname{Ig} \beta$ (also known as CD79B) heterodimer (FIG. 2). Upon antigen binding to the BCR, a SRC family protein tyrosine kinase, most probably LYN, phosphorylates the Iga and Ig $\beta$ immunoreceptor tyrosinebased activation motifs (ITAMs), thereby creating docking sites for $\mathrm{SYK}^{40}$. In parallel, LYN phosphorylates tyrosine residues in the cytoplasmic tail of the BCR co-receptor $\mathrm{CD} 19$, which enables the binding and activation of PI3K and $\mathrm{VAV}^{41,42}$. Besides CD19, cytoplasmic B cell adapter for PI3K (BCAP) can also recruit PI $3 \mathrm{~K}^{43}$, which indicates a redundancy in activating PI3K after triggering the BCR. PI3K generates PIP3, which is an important second messenger for activating downstream pathways (FIG. 2). PI3K attracts BTK to the cell membrane through a PIP3-PH domain interaction ${ }^{44}$, which allows SYK and LYN to fully activate BTK by trans-phosphorylation at Y551 (REFS 24,45) (discussed above). BTK activation can be regulated by the phosphatases PTEN and $\mathrm{SH} 2$ domain-containing inositol-5'-phosphatase-1 (SHIP1; also known as INPP5D), which dephosphorylate PIP3 and thereby inhibit BTK membrane association. Once SYK is activated, signalling is propagated to downstream effectors by the recruitment and phosphorylation of the $\mathrm{SH} 2$ domain-containing leukocyte protein of $65 \mathrm{kDa}$ (SLP65; also known as BLNK and BASH), which serves as a scaffold for various signalling molecules, including SYK, BTK and its crucial substrate phospholipase C- $\gamma 2$ (PLC $\gamma 2)^{46,47}$.

Downstream targets of BTK. The SLP65-mediated recruitment of BTK and PLC 2 completes the formation of so-called micro-signalosomes, which comprise VAV, PI3K, BTK, SLP65 and PLC 22 (REF. 48) (FIG. 2). BTK is mostly responsible for PLC $\gamma 2$ phosphorylation at positions $\mathrm{Y} 753$ and $\mathrm{Y} 759$, which is essential for the lipase activity of PLC $\gamma 2$ (REF. 49). Moreover, independent of its kinase activity, BTK can recruit phosphatidylinositol-4-phosphate 5-kinase (PIP5K), thereby stimulating a positive-feedback loop that generates phosphatidylinositol 4,5-bisphosphate (PIP2), which serves as a substrate for both PI3K and PLC $\gamma 2$ (REF. 50).This feed-forward mechanism allows BTK to stimulate the PIP3 production that is required for its own activation. In agreement with these findings in mature A20 B cells, we noted that during B cell development in mice BTK function is partly independent of its kinase activity ${ }^{29}$.

Upon activation by BTK, PLC $\gamma 2$ cleaves PIP 2 to generate two second messengers, inositol triphosphate (IP3) and diacylglycerol (DAG), which activate diverging and partially overlapping signalling pathways. IP3 is involved in regulating intracellular $\mathrm{Ca}^{2+}$ levels and thereby activates nuclear factor of activated $\mathrm{T}$ cells (NFAT) transcription factors via calmodulin. DAG mediates activation of protein kinase $\mathrm{C} \beta(\mathrm{PKC} \beta)$, which induces RAS signalling-dependent phosphorylation of the extracellular signal-regulated kinases ERK1 and ERK2. Unlike ERK1 and ERK2, other MAPKs, such as p38 and JUN N-terminal kinase (JNK), can be induced by PLC $\gamma 2$ without intermediate signalling via RAS $S^{51}$. Importantly, $\mathrm{PKC} \beta$ also activates the NF- $\mathrm{KB}$ pathway through a scaffold complex that includes caspase recruitment domain-containing protein 11 (CARD11; also known as CARMA1 and BIMP1), BCL-10 and mucosaassociated lymphoid tissue lymphoma translocation protein 1 (MALT1) ${ }^{52}$ (FIG. 2). Whereas BCR stimulation does not induce NF- $\kappa$ B activation in BTK-deficient B cells, $T$ cell-dependent NF- $\kappa B$ activation that is mediated by $\mathrm{CD} 40$ ligand $(\mathrm{CD} 40 \mathrm{~L})-\mathrm{CD} 40$ interaction remains unaffected $^{53,54}$, and this gives an explanation of why B cells in Btk-deficient mice can respond to T cell-dependent antigens but not to $\mathrm{T}$ cell-independent antigens ${ }^{10}$.

In addition, BTK connects BCR signalling to actin dynamics that are involved in BCR internalization, processing and antigen presentation. BTK directly interacts with Wiskott-Aldrich syndrome protein (WASP) and can activate it by inducing its phosphorylation,

\section{Box 1 Phenotype of Bruton's tyrosine kinase deficiency in humans and mice}

Loss-of-function mutations in the Bruton's tyrosine kinase (BTK) gene in humans cause the primary immunodeficiency disease X-linked agammaglobulinaemia (XLA), which was first described by Bruton in 1952 (reviewed in REF. 3). XLA is a rare disease (with an incidence of 1 per 380,000 live births in the United States) ${ }^{152}$ that is characterized by an almost complete block of $B$ cell development at the pre- $B$ cell stage. In the bone marrow, the number of pre-B cells expressing the immunoglobulin- $\mu$ heavy $(\mathrm{lgH} \mu)$ chain in their cytoplasm is variable but often reduced. Pre-B cells in patients with XLA are small in size, which suggests that BTK is essential for their proliferation ${ }^{153}$. Patients have few circulating B cells, and these cells have an aberrant immature lg $\mathrm{M}^{\text {high }}$ phenotype, as well as a distinct antibody repertoire that is enriched in autoreactive $B$ cell receptors (BCRs) ${ }^{3,154}$. Serum immunoglobulin levels of all subclasses are very low. Affected boys usually present with severe or recurrent infections with encapsulated bacteria - predominantly otitis media, sinusitis and pneumonia. In addition, gastrointestinal infections that are caused by Giardia parasites and skin infections are frequently found, but meningitis and osteomyelitis are less common ${ }^{152}$. Current treatments involve antibiotics and intravenous or subcutaneous immunoglobulin substitution therapy. Although BTK is abundantly expressed in myeloid cells, patients with XLA do not show substantial defects in innate immune responses. Moreover, patients who are maintained on sufficient lg therapy are generally quite healthy, which suggests that BTK is dispensable outside the B cell compartment.

By contrast, Btk-deficient mice - either the X-linked immunodeficiency (XID) CBA/N strain that harbours the R28C Btk mutation, or mice with a targeted disruption of the Btk gene - show a mild phenotype $\mathrm{e}^{5,6,10,155}$. Although minor defects in pre-BCR checkpoint function have been observed ${ }^{156}$, Btk deficiency is mainly characterized by impaired differentiation and survival of mature B cells. B cell numbers in the spleen and the lymph nodes are reduced by $\sim 50 \%$, serum levels of $\lg \mathrm{M}$ and $\lg \mathrm{G} 3$ are low, but other immunoglobulin subclasses are normal. 


\section{Table 1 | Bruton's tyrosine kinase inhibitors in preclinical development and clinical trials}

\begin{tabular}{|c|c|c|c|c|c|}
\hline Name and structure & $\mathrm{IC}_{50}$ & Mode of action & Selectivity & Clinical trials & Refs \\
\hline $\begin{array}{l}\text { Ibrutinib (also known as PCl-32765) } \\
\text { (Pharmacyclics) }\end{array}$ & $0.5 \mathrm{nM}$ & $\begin{array}{l}\text { - Irreversible, } \\
\text { covalent binding } \\
\text { to C } 481 \\
\text { - Inhibition of BTK } \\
\text { kinase activity } \\
\text { - Does not prevent } \\
\text { BTK Y551 } \\
\text { phosphorylation }\end{array}$ & $\begin{array}{l}\text { - High level of } \\
\text { cross-reactivity with BLK } \\
\text { and BMX }\left(\mathrm{IC} \mathrm{C}_{50}=0.5 \mathrm{nM}\right) \text {, } \\
\text { which contain a cysteine } \\
\text { that aligns with C } 481 \\
\text { in BTK } \\
\text { - Cross-reactivity with } \\
\text { ITK }\left(\mathrm{IC} \mathrm{C}_{50}=11 \mathrm{nM}\right) \\
\text { affects } \\
\text { immun cell-mediated } \\
\text { disease models } \\
\text { - Low cross-reactivity with } \\
\text { TEC }\left(\mathrm{IC} \mathrm{C}_{50}=78 \mathrm{nM}\right), \mathrm{LYN} \\
\left(\mathrm{IC} \mathrm{C}_{50}=200 \mathrm{nM}\right) \text { and SYK } \\
\left(\mathrm{IC}_{50}>10,000 \mathrm{nM}\right)\end{array}$ & $\begin{array}{l}\text { Of } 48 \text { studies: } \\
\text { - Reported: Phase I in } \\
\text { CLL, DLBCL, follicular } \\
\text { lymphoma, MCL and WM; } \\
\text { high response rates in } \\
\text { Phase II in CLL and MCL } \\
\text { - Ongoing: CLL (Phases I, II } \\
\text { and III); MCL (Phases II, } \\
\text { III and IV); DLBCL } \\
\text { (Phases II and III); multiple } \\
\text { myeloma (Phase II); } \\
\text { WM (Phase II); follicular } \\
\text { lymphoma (Phases I and II) } \\
\text { and HCL (Phase II) }\end{array}$ & $\begin{array}{c}17, \\
19, \\
20\end{array}$ \\
\hline $\begin{array}{l}\text { CC-292 (also known as AVL-292) } \\
\text { (Celgene) }\end{array}$ & $<0.5 \mathrm{nM}$ & $\begin{array}{l}\text { - Irreversible, } \\
\text { covalent binding } \\
\text { to C481 } \\
\text { - Inhibition of BTK } \\
\text { kinase activity } \\
\text { - Does not prevent } \\
\text { BTK Y551 } \\
\text { phosphorylation }\end{array}$ & $\begin{array}{l}\text { - High cross-reactivity } \\
\text { with BMX }\left(I C_{50}=0.7 \mathrm{nM}\right) \text {, } \\
\text { which contains a } \\
\text { cysteine that aligns with } \\
\text { C481 in BTK } \\
\text { - Limited cross-reactivity } \\
\text { with TEC }\left(\mathrm{IC} \mathrm{C}_{50}=6.2 \mathrm{nM}\right) \\
\text { and ITK }\left(\mathrm{IC} \mathrm{C}_{50}=36 \mathrm{nM}\right) \\
\text { - Low cross-reactivity } \\
\text { with LYN }\left(\mathrm{IC} \mathrm{C}_{50}=\right. \\
4,400 \mathrm{nM}) \text { and SYK } \\
\left(\mathrm{IC} \mathrm{C}_{50}>10,000 \mathrm{nM}\right)\end{array}$ & $\begin{array}{l}\text { Of four studies: } \\
\text { - Safety studies in CLL } \\
\text { - Escalating dose study in } \\
\text { CLL and WM } \\
\text { - Phase IB study in B cell } \\
\text { lymphoma }\end{array}$ & 163 \\
\hline $\begin{array}{l}\text { CGI-1746 } \\
\text { (CGI Pharmaceuticals) }\end{array}$ & $1.9 \mathrm{nM}$ & $\begin{array}{l}\text { - Reversible } \\
\text { binding to } \\
\text { unphosphorylated } \\
\text { BTK in SH3 } \\
\text { domain, } \\
\text { stabilizing BTK } \\
\text { in an inactive } \\
\text { conformation } \\
\text { - Blocks BTK } \\
\text { phosphorylation } \\
\text { at Y551 and Y223 }\end{array}$ & $\begin{array}{l}\text { - Superior BTK selectivity } \\
\text { - No or minimal } \\
\text { cross-reactivity with } \\
\text { TEC family kinases } \\
\text { (ITK IC } C_{50}=4,270 \mathrm{nM} \text {; } \\
\text { TEC IC } C_{50}>10,000 \mathrm{nM} \text { and } \\
\text { BMX IC }=1,870 \mathrm{nM} \text { ) or } \\
\text { SRC family kinases } \\
(\text { LYN IC } \\
\text { SRC IC } C_{50}=10,000 \mathrm{nM} \text {; }\end{array}$ & Preclinical & 146 \\
\hline $\begin{array}{l}\text { GDC-0834 } \\
\text { (Genentech/Gilead) }\end{array}$ & $5.9 \mathrm{nM}$ & $\begin{array}{l}\text { Highly selective, } \\
\text { reversible and } \\
\text { ATP-competitive } \\
\text { small-molecule } \\
\text { inhibitor of BTK, } \\
\text { being developed as } \\
\text { a therapeutic agent } \\
\text { for rheumatoid } \\
\text { arthritis }\end{array}$ & Unknown & $\begin{array}{l}\text { Has shown efficacy in } \\
\text { mouse autoimmune } \\
\text { models, but its use in } \\
\text { treatment of human } \\
\text { disease is challenged by } \\
\text { the rapid hydrolysis of the } \\
\text { active form to an inactive } \\
\text { metabolite in healthy } \\
\text { human volunteers; no } \\
\text { clinical studies }\end{array}$ & $\begin{array}{l}147, \\
165\end{array}$ \\
\hline $\begin{array}{l}\text { Dasatinib (also known as BMS-354825) } \\
\text { (Bristol-Myers Squibb) }\end{array}$ & $5.0 \mathrm{nM}$ & $\begin{array}{l}\text { Binds to the } \\
\text { ATP-binding } \\
\text { site of the active } \\
\text { and inactive } \\
\text { conformation of } \\
\text { the ABL kinase } \\
\text { domain }\end{array}$ & $\begin{array}{l}\text { Reversible multi-kinase } \\
\text { inhibitor, originally } \\
\text { developed as a SRC } \\
\text { and ABL inhibitor; high } \\
\text { cross-reactivity with the } \\
\text { TEC family kinases TEC } \\
\left(\text { IC } C_{50}=297 \mathrm{nM} \text { ) and the }\right. \\
\text { SRC family kinases LYN } \\
\text { and SRC }\end{array}$ & $\begin{array}{l}\text { A total of } 230 \text { studies } \\
\text { (completed and ongoing): } \\
\text { Phase I-IV studies in } \\
\text { BCR-ABL-positive patients } \\
\text { with ALL, CML, CLL and } \\
\text { multiple myeloma }\end{array}$ & 116 \\
\hline
\end{tabular}


Table 1 (cont.) | Bruton's tyrosine kinase inhibitors in preclinical development and clinical trials

\begin{tabular}{|c|c|c|c|c|c|}
\hline Name and structure & $\mathrm{IC}_{50}$ & Mode of action & Selectivity & Clinical trials & Refs \\
\hline LFM-A13 & $17.2 \mu \mathrm{M}$ & $\begin{array}{l}\text { Reversible } \\
\text { inhibitor; binds } \\
\text { to the catalytic } \\
\text { pocket of the } \\
\text { kinase domain }\end{array}$ & $\begin{array}{l}\text { Cross-reactivity with } \\
\text { PLK; does not affect the } \\
\text { enzymatic activity of } \\
\text { other protein tyrosine } \\
\text { kinases, including JAK1, } \\
\text { JAK3, HCK, epidermal } \\
\text { growth factor receptor } \\
\text { kinase and insulin } \\
\text { receptor kinase }\end{array}$ & Preclinical & 16 \\
\hline $\begin{array}{l}\text { ONO-4059 } \\
\text { (Ono Pharmaceutical) } \\
\text { (Structure unavailable) }\end{array}$ & $2.2 \mathrm{nM}$ & $\begin{array}{l}\text { Reversible covalent } \\
\text { binding to BTK }\end{array}$ & $\begin{array}{l}\text { - High cross-reactivity to } \\
\text { TEC }\left(\mathrm{IC}_{50}=5.3 \mathrm{nM}\right) \\
\text { - Low cross-reactivity to } \\
\text { LCK }\left(\mathrm{IC} \mathrm{C}_{50}=790 \mathrm{nM}\right), \mathrm{FYN} \\
\left(\mathrm{IC} \mathrm{C}_{50}=2,200 \mathrm{nM}\right) \text { and } \mathrm{LYN} \\
\left(\mathrm{IC}_{50}=3,500 \mathrm{nM}\right)\end{array}$ & $\begin{array}{l}\text { Ongoing studies in } \\
\text { patients with refractory } \\
\text { and relapsed CLL or NHL } \\
\text { (Phase I) }\end{array}$ & 166 \\
\hline
\end{tabular}

ALL, acute lymphoblastic leukaemia; BLK, B lymphoid tyrosine kinase; BMX, bone marrow-expressed kinase; BTK, Bruton's tyrosine kinase; CLL, chronic lymphocytic leukaemia; CML, chronic myeloid leukaemia; DLBCL, diffuse large B cell lymphoma; $\mathrm{HCL}$, hairy cell leukaemia; IC ${ }_{50}$, half-maximal inhibitory concentration; ITK, inducible T-cell kinase; JAK, Janus kinase; MCL, mantle cell lymphoma; NHL, non-Hodgkin's lymphoma; PLK, polo-like kinase; SH3, SRC homology 3; SLK, Ste20-like kinase; SYK, spleen tyrosine kinase; WM, Waldenström's macroglobulinaemia.

Germinal centres

Structures found in the follicles of secondary lymphoid tissues that are composed of proliferating B cells that are induced to mutate

antibody-encoding genes through somatic hypermutation after contact with antigen and Thelper cells.

Follicular dendritic cells (FDCs). Cells of mesenchymal origin that are found in B cell follicles of lymphoid tissues and that present antigen to B cells in immune complexes with antibodies binding to $\mathrm{FC}$ receptors on their cell surface.

Interleukin-7 receptor signalling

(IL-7R signalling). The cytokine

IL-7 is produced by bone marrow stromal cells and promotes proliferation and survival of B cell precursors in mice, but it does not seem to have a crucial role in human B cell development. by activating the small GTPase cell division control protein 42 (CDC42) via VAV phosphorylation and by increasing PIP2 synthesi ${ }^{50,55}$. Moreover, BTK can promote RAC-dependent actin filament rearrangement and its $\mathrm{PH}$ domain can directly interact with actin filaments $^{56-58}$ (FIG. 1). In the absence of BTK, BCR aggregation into clusters and $\mathrm{B}$ cell spreading after the binding of antigen to the $\mathrm{BCR}$ is compromised. Reorganization of the actin cytoskeleton after BCR engagement also controls $\alpha 4 \beta 1$ integrin-mediated $B$ cell adhesion to vascular cell adhesion molecule 1 (VCAM1) and to fibronectin. $\alpha 4 \beta 1$ integrin-mediated B cell adhesion requires BTK, PLC $\gamma 2, \mathrm{Ca}^{2+}$ release and PKC $\beta$, but not ERK1 or ERK2 (REF. 59). This pathway is particularly important in germinal centres, where B cell survival is dependent on interactions with follicular dendritic cells (FDCs), which are mediated by the $\alpha 4 \beta 1$ integrin and $\alpha \mathrm{L} \beta 2$ integrin on $\mathrm{B}$ cells, as well as by VCAM1 and intercellular adhesion molecule 1 (ICAM1) on FDCs ${ }^{60}$.

$B T K$ in pre-BCR signalling. It is assumed that the signalling pathways that are mediated by pre-BCR and $B C R$ are similar. This is supported by evidence for the formation of a raft-associated $\mathrm{Ca}^{2+}$ signalling module composed of tyrosine-phosphorylated LYN, SYK, SLP65, PI3K, BTK, VAV and PLC $\gamma 2$ upon engagement of the human pre$\mathrm{BCR}^{61}$. In mice, pre- $\mathrm{BCR}$ signalling functionally intersects with the interleukin-7 receptor signalling (IL-7R signalling) pathway, which, in addition to Janus kinase 3 (JAK3)-signal transducer and activator of transcription 5 (STAT5) signalling, also activates SRC family kinases and the ERK pathway. IL-7R and pre-BCR signalling synergistically induce proliferation in pre-B cells ${ }^{13}$.
Mice that are deficient for crucial pre-BCR molecules, such as SYK, SLP65, BTK and PLC 2 2, only show a partial developmental block at the pre-B cell stage. This can be explained by the additional expression of homologous signalling molecules that were previously thought to be exclusively expressed in T cells, including $\zeta$-associated protein of $70 \mathrm{kDa}$ (ZAP70), linker for activation of T cells (LAT), SLP76, TEC and PLC $\gamma 1$. Interestingly, the SYK homologue ZAP70 is also expressed in CLL, where it is associated with increased BCR and NF- $\kappa B$ signalling and a poor prognosis ${ }^{62}$. Pre-BCR signalling can be initiated in a ligand-independent and cell-autonomous manner, and it was recently shown to require interaction between the $\lambda 5$ surrogate light chain (SLC) component and $\mathrm{N}$-linked glycosylated residues of the $\mathrm{IgH} \mu \mathrm{chain}^{63}$. However, it remains possible that pre-B cell proliferation is increased by interaction with particular self-antigens, stromal cell-associated galactin 1 or heparan sulphate ${ }^{64,65}$.

Interestingly, mice that are deficient for Slp65 not only show a partial arrest of B cell development at the pre- $B$ cell stage but also have a high incidence of pre-B cell leukaemia ${ }^{66}$. Slp65-deficient leukaemic pre-B cells express high levels of pre-BCR on the cell surface, but this is unlikely to contribute to their strong proliferative capacity in vivo, because transgenic overexpression of SLC does not induce or increase the development of leukaemia ${ }^{67}$. Rather, in Slp65-deficient leukaemic pre-B cells the JAK3-STAT5 signalling pathway is constitutively activated, mostly owing to autocrine IL-7 production ${ }^{68}$. In normal pre-B cells, SLP65 downregulates IL-7-mediated pre-B cell proliferation and survival through the direct inhibition of JAK3. $B t k$-deficient mice do not develop pre-B cell leukaemia; 


\section{Box 2 | The TEC kinase family}

The TEC family of non-receptor tyrosine kinases consists of Bruton's tyrosine kinase (BTK), as well as four additional members: TEC, inducible T cell kinase (ITK), resting lymphocyte kinase (RLK) and bone marrow-expressed kinase (BMX)22.

Three TEC kinase family members, ITK, TEC and RLK, are expressed in the T cell lineage. In thymocytes and naive T cells, ITK is the most highly expressed family member and, parallel to BTK, it is activated in response to T cell receptor (TCR) engagement and is required for downstream phosphorylation of phospholipase $C \gamma 1$ $(\mathrm{PLC} \gamma 1)$ and for $\mathrm{Ca}^{2+}$ mobilization ${ }^{157}$. Moreover, ITK contributes to TCR-induced cytoskeleton regulation, integrin activation, chemokine signalling and cytokine production. Although ITK and RLK show partial compensatory activity during T cell development, they have differential effects in $\mathrm{CD} 4^{+}$T helper cell polarization ${ }^{157}$. ITK loss-of-function mutations cause a rare immunodeficiency syndrome that is characterized by the inability to control Epstein-Barr virus (EBV) infection, resulting in EBV-associated B cell lymphoproliferative disorders ${ }^{158}$.

Although TEC is expressed throughout B cell and T cell development, Tec-deficient mice do not show an immunological phenotype. Btk; Tec double-deficient mice, however, manifest a severe arrest of B cell development at the pre-B cell stage. Therefore, phenotypic differences between X-linked immunodeficiency (XID) in mice and X-linked agammaglobulinaemia (XLA) in humans might partly be explained by the ability of TEC to compensate for BTK in mice ${ }^{159}$. Moreover, Btk; Tec double-deficient mice show severe osteopetrosis that is caused by defective osteoclast function ${ }^{126}$.

$\mathrm{BMX}$ is expressed in myeloid cells, where it regulates the secretion of pro-inflammatory cytokines, epithelial cells, endothelial cells and fibroblasts ${ }^{160}$. Like BTK, it interacts with the Toll-like receptor (TLR) pathway adaptors myeloid differentiation primary response 88 (MYD88) and MYD88 adaptor-like protein (MAL). Most importantly, in arterial endothelial cells, BMX is involved in transduction of vascular endothelial growth factor (VEGF) signals, and it thereby actively contributes to tumour angiogenesis and growth ${ }^{161}$. BMX is expressed in several cancer types and was shown to activate signal transducer and activator of transcription 3 (STAT3) signalling in glioblastoma cancer stem cells.

Pre-B cell acute

lymphoblastic leukaemia

(Pre-B ALL). ALL is the most

common childhood

malignancy, derived from the precursor B cell compartment in the bone marrow. however, independent of its kinase activity, BTK does cooperate with SLP65 to regulate IL-7-mediated pre-B cell proliferation and survival, which suggests that BTK could function as a tumour suppressor ${ }^{69,70}$. Somatic BTK or SLP65 mutations have not been observed in human childhood pre-B cell acute lymphoblastic leukaemia (pre-B ALL), whereas kinase-deficient BTK splice variants and a deficiency of SLP65 protein owing to aberrant splicing have been documented ${ }^{71-73}$. Further studies are required to determine whether defective SLP65 or BTK expression has a role in the oncogenic transformation of pre-B cells in ALL.

\section{Role of BTK in other signalling pathways}

BTK is expressed in many haematopoietic cell types ${ }^{14,21}$, where its involvement in various pathways has been defined $^{3}$. Likewise, in B cells, BTK participates in multiple pathways, including chemokine receptor and TLR signalling.

BTK and chemokine receptor signalling. Biochemical analyses and in vitro adhesion and migration assays have established the involvement of BTK in chemokine receptor pathways that are essential for B cell trafficking, tissue homing and homeostasis. BTK is a key signalling molecule for the chemokine receptors CXCR4 and CXCR5 (REF. 74). CXC-chemokine ligand 12 (CXCL12; also known as SDF1), which is highly expressed by stromal cells in the bone marrow and in germinal centres, induces BTK activation ${ }^{74}$, most probably by direct interactions between BTK and the CXCR4-linked heterotrimeric G protein subunits (FIG. 3a). Both Ga and G $\beta \gamma$ subunits can directly bind to the $\mathrm{PH}$ domain and the adjacent TH domain of BTK ${ }^{75,76}$. G $\beta \gamma$ subunits might also bind to the catalytic domain ${ }^{77}$. Although $G \beta \gamma$ subunits stimulate membrane translocation, the membrane anchorage of BTK is dependent on PIP3 (REF. 77). Because a reduction of CXCL12-controlled migration was found in B cells that lacked LYN or SYK, these kinases were postulated to activate BTK after CXCR4 ligation ${ }^{74}$. This was confirmed by the finding that CXCL12-induced phosphorylation of BTK at Y551 is reduced in the presence of a SYK inhibitor $^{78}$. In agreement with the idea that BTK has a key role in chemokine receptor signalling, treatment of MCL and CLL cells with ibrutinib inhibited CXCL12-induced and CXCL13-induced phosphorylation of PLC $\gamma 2$, ERK1, ERK2, JNK and AKT, as well as cell adhesion and migration, in vitro ${ }^{78-80}$. Ibrutinib also reduced CC-chemokine ligand 19 (CCL19)-induced adhesion and migration, which is mediated by CC-chemokine receptor 7 (CCR7) - a receptor that is highly expressed on CLL cells.

A role for BTK in chemokine signalling in vivo was first demonstrated by adoptive transfer experiments with Btk-deficient B cells in mice, which showed that B cell homing to lymph nodes was particularly affected ${ }^{74}$. Recent data from clinical trials show that ibrutinib treatment results in an egress of malignant cells into the circulation $^{19,20}$, which indicates that BTK function is essential for the homing of B cells into lymphoid tissues in humans (discussed below).

BTK and TLR signalling. A role for BTK in TLR signalling was first shown by the finding that the proliferation of Btk-deficient B cells is reduced in response to the TLR4 ligand bacterial lipopolysaccharide (LPS) ${ }^{10}$. Upon activation, most TLRs recruit the adaptor myeloid differentiation primary response 88 (MYD88). Exceptions to this include TLR3 (a receptor that is specific for detecting viral double-stranded RNA), which uses TIR domain-containing adaptor protein inducing interferon- $\beta$ (TRIF; also known as TICAM1), and TLR4, which can signal both via a MYD88-dependent pathway (FIG. 3b) and via a MYD88-independent pathway $^{81}$. TLR signalling induces the downstream transcription factors NF- $\kappa \mathrm{B}$, activator protein 1 (AP1) and interferon regulatory factor 3 (IRF3), which, in B cells, results in upregulation of activation markers, proliferation, antibody secretion, class switch recombination and the production of pro-inflammatory cytokines. BTK can directly interact with cytoplasmic Toll/IL-1 receptor (TIR) domains of most TLRs, as well as with the downstream adaptors MYD88, TRIF and MYD88 adaptor-like protein (MAL; also known as TIRAP), and IL-1R-associated kinase 1 (IRAK1) ${ }^{82-85}$ (FIG. 3b). How B cells integrate adaptive BCR and innate TLR activation is an area of intensive research. Interestingly, TLR9 and BCR stimulation can synergistically induce the production of IL- 6 , whereby BTK is required for colocalization of TLR9 and BCR in an autophagosomelike compartment ${ }^{86}$. Given that BCR signalling is initiated at the cell surface and continues to activate MAPK 
Anergic response

A reversible programme that is characterized by low levels of

$B$ cell receptor $(B C R)$

expression and limited

BCR-induced activation of

signalling molecules, which

serves to silence autoreactive B cells

Nurse-like cells

(NLCs). Peripheral blood

monocyte-derived adherent cells to which chronic

lymphocytic leukaemia (CLL) $B$ cells become attached. This interaction can protect CLL cells from spontaneous apoptosis in vitro. as it traffics to intracellular compartments ${ }^{87}$, it is conceivable that in endosomes, TLR and BCR signalling are interconnected by BTK.

\section{BTK signalling in B cell malignancies}

Evidence is accumulating that BTK activity is crucial for the survival or proliferation of leukaemic B cells, either in a B cell-intrinsic manner or in the context of the tumour microenvironment. Here, we discuss the role of BTK and the effects of BTK inhibition for individual B cell malignancies (summarized in TABLE 2).

CLL. CLL is characterized by the accumulation of non-proliferating monoclonal $\mathrm{CD}^{+}$mature $\mathrm{B}$ cells in the blood. CLL B cells generally have low surface IgM expression and show an anergic response to BCR ligation, which indicates chronic BCR internalization and signalling ${ }^{88}$. Continuous antigen binding in lymphoid tissues is thought to be essential to anergize CLL cells, because IgM-BCR unresponsiveness can be restored following in vitro culture ${ }^{89}$. Expansion of malignant CLL cells occurs in proliferation centres in lymph nodes where antigens, chemokines, TLR ligands and T cell co-stimulation provide important signals for survival, proliferation and migration $^{90}$. Patients who have CLL with hypermutated IgH chain V (IGHV) genes (M-CLL) have a more favourable prognosis than those with unmutated IGHV genes (U-CLL). Together with the highly restricted and biased IGHV gene repertoire in CLL, which is referred to as 'stereotyped BCRs', and the recent identification of the antigen specificity of particular CLL B cells, these findings strongly indicate that B cell proliferation that is driven by specific autoantigens or antigens derived from apoptotic

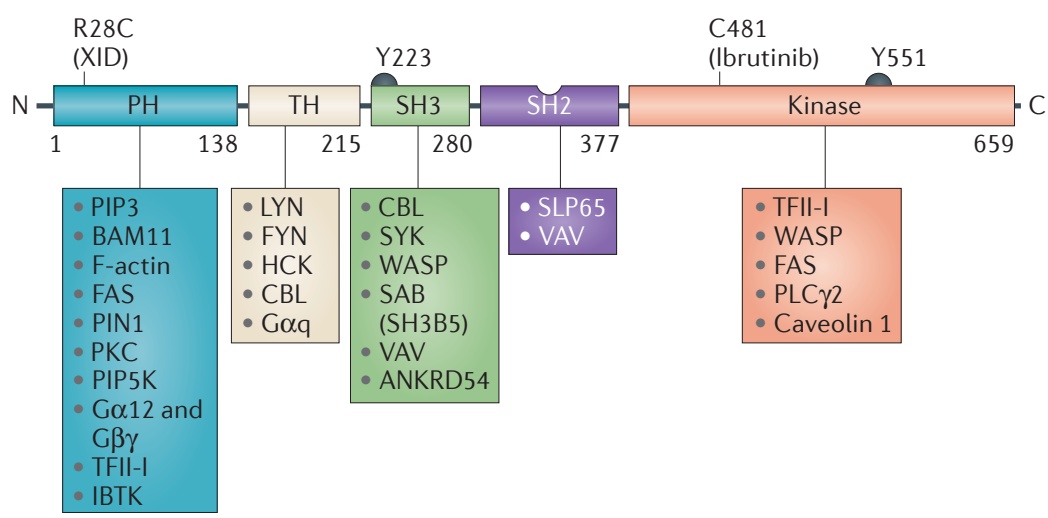

Figure 1 | Structure of Bruton's tyrosine kinase and interactions. The structure of Bruton's tyrosine kinase (BTK) is shown, with the five different domains. The position of the R28C loss-of-function mutation that is present in X-linked immunodeficiency (XID) mice, the position of two tyrosine $(\mathrm{Y})$ phosphorylation sites and the binding site of ibrutinib are shown. For each domain, interacting signalling molecules are shown. In addition, myeloid differentiation primary response 88 (MYD88), IL-1R-associated kinase (IRAK) and Toll/IL-1 receptor (TIR) domains of various Toll-like receptors (TLRs) have been shown to bind to BTK, but the interacting domain is unknown. ANKRD54, ankyrin repeat domaincontaining protein 54; F-actin, filamentous actin; IBTK, inhibitor of Bruton's agammaglobulinemia kinase; PH, pleckstrin homology; PIP3, phosphatidylinositol-3,4,5,trisphosphate; PIP5K, phosphatidylinositol-4-phosphate 5-kinase; PIN1, peptidyl-prolyl cis-trans isomerase NIMA-interacting 1; PKC, protein kinase C; PLC $\gamma 2$, phospholipase C 2 ; SH, SRC homology; SLP65, SH2 domain-containing leukocyte protein of $65 \mathrm{kDa}$; SYK, spleen tyrosine kinase; TH, TEC homology; WASP, Wiskott-Aldrich syndrome protein. cells or pathogens is essential for CLL pathogenesis ${ }^{91,92}$ In contrast to this ligand-dependent BCR signalling, CLL BCRs showed $\mathrm{Ca}^{2+}$ signalling in the apparent absence of a ligand, which resulted from self-recognition through an internal BCR epitope in the second framework region of the IgH chain ${ }^{93}$. The two models of BCR signalling, one dependent on external ligands and the other dependent on an internal BCR epitope, might not be mutually exclusive, because cell-autonomous signalling could be augmented by an antigen-driven response.

Several findings show that BTK signalling substantially contributes to the initiation or maintenance of CLL. BTK is overexpressed in CLL B cells and is constitutively phosphorylated in a proportion of CLL samples $^{94}$. In a CLL mouse model, Btk deficiency abrogated tumour formation, whereas transgenic BTK overexpression increased tumour incidence and overall mortality ${ }^{39,95}$. The treatment of CLL cells with ibrutinib in vitro diminished cell survival and proliferation ${ }^{80,94}$, and it abolished BCR-stimulated AKT and ERK phosphorylation $^{78,80}$, as well as VCAM1-mediated adhesion ${ }^{78}$ and the expression of lymphocyte cytosolic protein 1 (LCP1; also known as plastin 2), which is a filamentous actin (F-actin) crosslinking molecule that is essential for CXCL12-mediated migration ${ }^{96}$.

BTK signalling might support CLL cell migration to proliferative centres in lymph nodes, because ibrutinib treatment of CLL cells in vitro effectively blocked CXCL12-induced and CXCL13-induced migration ${ }^{78,80}$. In addition, ibrutinib-treated CLL cells showed reduced viability in vitro when cultured with B cell-activating factor (BAFF; also known as TNFSF13B), tumour necrosis factor (TNF), IL-6, IL-4 and CD40L ${ }^{97}$, which suggests that BTK inhibition might counteract the effects of pro-survival factors in the CLL microenvironment. The potential for disruption of co-stimulatory feedback in lymph node microenvironments was also shown by reduced CLL cell survival, proliferation and CCL3 (also known as MIP1 $\alpha$ ) and CCL4 production when CLL cells were co-cultured with nurse-like cells (NLCs) ${ }^{80}$. The finding that ibrutinibtreated patients with CLL have a decline in serum CCL3 and CCL4 levels ${ }^{80}$ is particularly important because CCL3 is a strong marker of disease progression ${ }^{98}$.

Inhibition of BTK interferes with multiple pathways that are potentially important for CLL cell survival, proliferation and migration in vivo. However, the effects on cell migration may be decisive in CLL. The ibrutinibinduced lymphocytosis that is observed in both patients with CLL and mouse CLL adoptive transfer models ${ }^{19,80}$ shows the effective expulsion of CLL cells out of the nursing environment of lymph nodes, thereby depriving CLL cells from multiple activating signals, including antigenic BCR stimulation ${ }^{90}$.

$M C L$. The remarkably biased BCR repertoire of MCL suggests a crucial role for antigenic stimulation in its pathogenesis $^{99}$. The antigens that are involved are unknown, but they probably differ from those in CLL, because the stereotypical BCR subsets are different in MCL and $\mathrm{CLL}^{99}$. A pro-survival role of BCR signalling is suggested by the observation of constitutive phosphorylation of LYN, 
SLP65, SYK and PKC $\beta$ in a limited panel of patients ${ }^{100,101}$. In addition, it was found that amplification of the SYK gene and SYK protein overexpression occurred ${ }^{102}$. Furthermore, MCL cells show constitutive activation of NF- $\kappa B$ and AKT, which might reflect BCR or TLR signalling ${ }^{103}$.

BTK is strongly expressed in $\mathrm{MCL}^{104}$, and increased BTK autophosphorylation at Y223 was observed in unstimulated primary MCL cells ${ }^{79}$. Parallel to

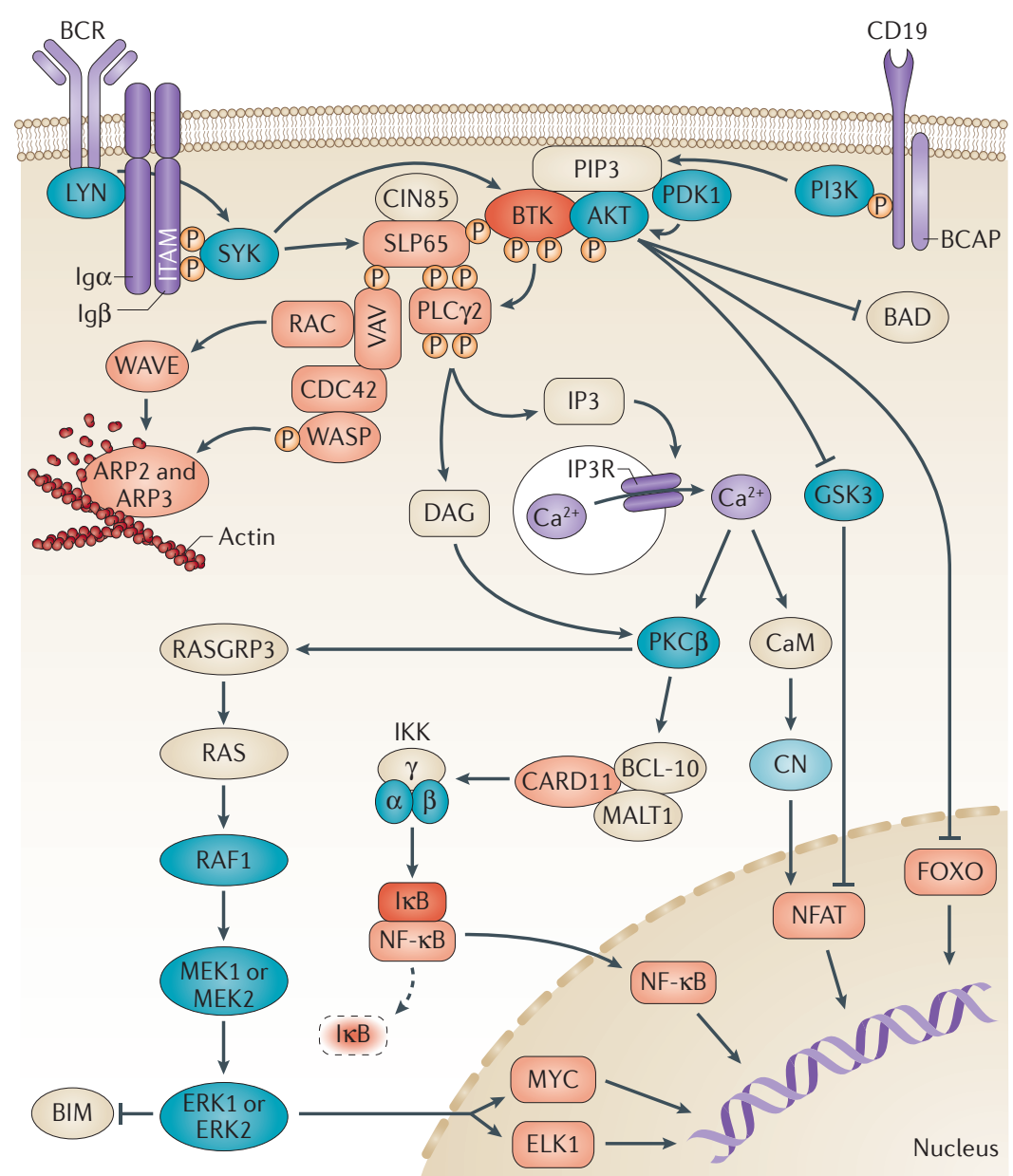

Figure 2 | Involvement of Bruton's tyrosine kinase in B cell receptor signalling. $B$ cell receptor $(B C R)$ signalling results in the formation of a micro-signalosome that is composed of VAV, PI3K, Bruton's tyrosine kinase (BTK), SH2 domain-containing leukocyte protein of $65 \mathrm{kDa}(\mathrm{SLP} 65)$ and phospholipase $\mathrm{C} \gamma 2$ (PLC $\gamma 2)$. BTK is mostly responsible for the activation of PLC $\gamma 2$, which leads to an influx of $\mathrm{Ca}^{2+}$ and the subsequent activation of the transcription factors nuclear receptor of activated T cells (NFAT) and nuclear factor- $\mathrm{KB}(\mathrm{NF}-\mathrm{\kappa B})$, as well as ERK1 or ERK2 activation. In addition, BTK activation leads to the activation of Wiskott-Aldrich syndrome protein (WASP), which induces cytoskeleton changes that are associated with $\mathrm{BCR}$ activation. Independently of $\mathrm{Ca}^{2+}$, AKT is activated via $\mathrm{PI} 3 \mathrm{~K}$, which phosphorylates $(\mathrm{P})$ forkhead box $\mathrm{O}$ (FOXO) transcription factors and thereby inactivates them. AKT also blocks pro-apoptotic proteins, including the $\mathrm{BH} 3$-only protein $B C L-2$ antagonist of cell death (BAD), thereby releasing it from $B C L-X_{L}$ and stabilizing MCL1. ARP, actin-related protein; BCAP, B cell adaptor for PI3K; BIM, BCL-2 interacting mediator of cell death; CaM, calmodulin; CARD11, caspase recruitment domain-containing protein 11 ; CIN85, CBL-interacting protein of $85 \mathrm{kDa}$; CN, calcineurin; DAG, diacylglycerol; GSK, glycogen synthase kinase; lg, immunoglobulin; lkB, inhibitor of $\kappa B$; IKK, inhibitor of NF- $\kappa$ B kinase; IP3, inositol trisphosphate; IP3R, IP3 receptor; ITAM, immunoreceptor tyrosine-based activation motif; MALT1, mucosa-associated lymphoid tissue lymphoma translocation protein 1; PDK1, 3-phosphoinositide-dependent protein kinase 1; PIP3, phosphatidylinositol-3,4,5,-trisphosphate; PKC, protein kinase C; SYK, spleen tyrosine kinase; RASGRP3, RAS guanyl-releasing protein 3. observations in CLL, ibrutinib treatment of primary MCL cells or cell lines resulted in reduced viability, as well as impaired adhesion and migration upon activation of the BCR or in response to CXCR4 or CXCR5 (REF. 79). Patients with MCL who receive intermittent or continuous ibrutinib treatment have recurrent lymphocytosis or a single episode of lymphocytosis, respectively ${ }^{79}$.

$A B C-D L B C L$. ABC-DLBCL cells are dependent on $\mathrm{NF}-\kappa \mathrm{B}$ signalling for survival and proliferation, and this is reflected by a high expression level of NF- $\kappa \mathrm{B}$ target genes $^{105}$ and high sensitivity to inhibition of NF- $\kappa B$ signalling ${ }^{106-109}$. This NF- $\kappa \mathrm{B}$ dependency can be explained by chronic activation of TLR or BCR signalling. Mutations in CARD11, as well as other mediators and regulators of NF- $\kappa \mathrm{B}$ signalling, occur in $~ 50 \%$ of patients with ABC-DLBCL. In $\sim 29 \%$ of patients with this disease, constitutive NF- $\kappa \mathrm{B}$ activation is mediated by an L265P gain-of-function mutation in MYD88 (REF. 110).

Importantly, knockdown of BCR signalling molecules induced the death of ABC-DLBCL cell lines that expressed unmutated CARD11 (REF. 18). Further support for a disease-promoting role of BCR signalling is derived from transcriptome analyses that show a BCR signalling signature ${ }^{111}$ and from various genetic alterations in DLBCL, including a mutation of CD79B in $\sim 18 \%$ of ABC-DLBCL cases. SYK amplification and downregulation of protein tyrosine phosphatase receptor-type O truncated (PTPROt), which can dephosphorylate SYK, additionally contribute to increased chronic BCR signalling ${ }^{112-115}$. Blocking chronic BCR signalling in ABC-DLBCL cell lines by dasatinib - a BCR-ABL inhibitor that can also inhibit the SRC family kinases and TEC family kinases, including BTK ${ }^{116}$ - effectively compromised the survival of CARD11 wild-type cell lines only ${ }^{18}$. Consistent with a crucial role for BTK in TLR and BCR signalling, ibrutinib treatment and RNA interference experiments showed that the survival of ABC-DLBCL cell lines with wild-type CARD11 relied on BTK activity ${ }^{18}$.

Waldenström's macroglobulinaemia. A commonly recurring L265P point mutation in MYD88 in patients with Waldenström's macroglobulinaemia (WM) results in a constitutively active form of MYD88 (REF. 117). In WM cell lines with this mutation, BTK is also constitutively active, although the mechanisms involved remain unclear. MYD88 ${ }^{\mathrm{L} 265 \mathrm{P}}$ was recently shown to bind to phosphorylated BTK in WM cells, which indicates that BTK might have a direct role in MYD88 ${ }^{\mathrm{L} 265 \mathrm{P}}$ signalling in these cells. Ibrutinib treatment of WM cells abrogated MYD88 ${ }^{\mathrm{L} 265 \mathrm{P}}-\mathrm{BTK}$ association and reduced NF- $\kappa \mathrm{B}$ activation ${ }^{118}$. In both WM cell lines and primary WM cells, ibrutinib induced apoptosis and increased the levels of apoptosis when IRAK1 and IRAK4 were also inhibited ${ }^{118}$. The efficacy of ibrutinib treatment in MYD88 ${ }^{\mathrm{L} 265 \mathrm{P}}$-mutant WM cells might therefore fully rely on the abrogation of NF- $\kappa \mathrm{B}$ activation. Nevertheless, it is conceivable that BTK inhibition might also affect BCR-mediated survival signals or homing, 
a

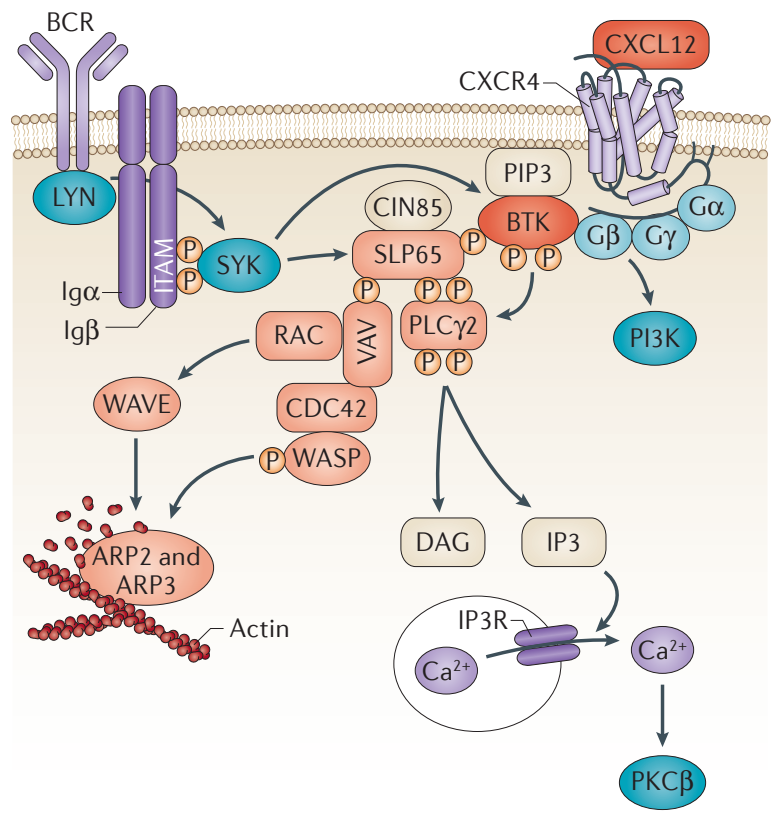

b

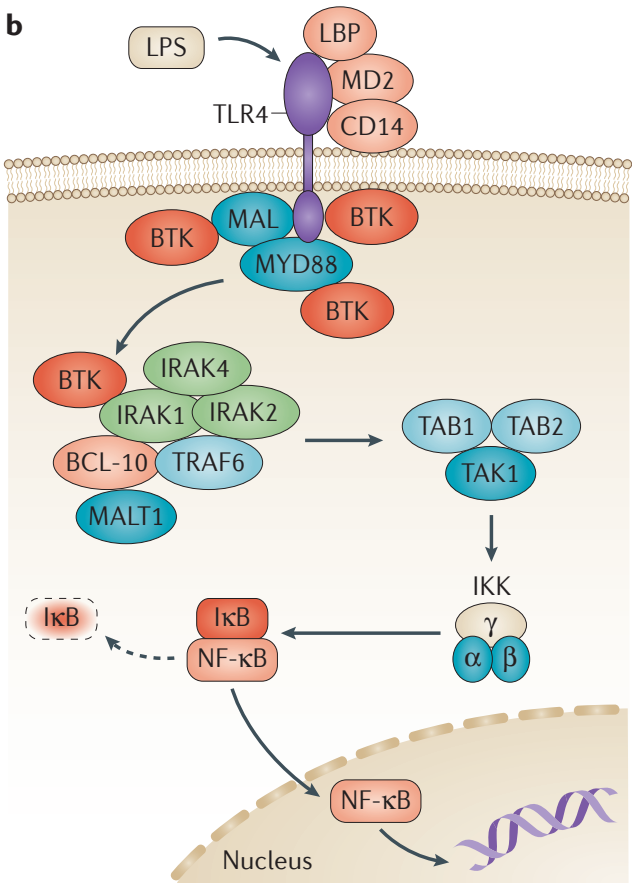

Figure 3 | Involvement of Bruton's tyrosine kinase in chemokine and Toll-like receptor signalling. a A schematic representation of the signalling pathways that underlie the dual role of Bruton's tyrosine kinase (BTK) in B cell receptor (BCR) and chemokine receptor signalling. BTK is a key signalling molecule for CXC-chemokine receptor 4 (CXCR4) and CXCR5. CXC-chemokine ligand 12 (CXCL12) induces BTK activation, most probably involving heterotrimeric G protein subunits, which are known to interact with BTK. $\mathbf{b} \mid$ A schematic representation of downstream signalling induced by lipopolysaccharide (LPS), as an example of myeloid differentiation primary response 88 (MYD88)-dependent Toll-like receptor (TLR) signalling. TLR signalling induces various downstream transcription factors, including nuclear factor- $\kappa B$ (NF-KB), which contributes to cellular proliferation. BTK has been shown to contribute to TLR signalling by interacting with five different molecules: the intercellular domains of most TLRs, the downstream adaptors MYD88 and MYD88 adaptor-like protein (MAL), IL-1R-associated kinase 1 (IRAK1) and TIR domain-containing adaptor protein inducing interferon- $\beta$ (TRIF (not shown) part of the MYD88-independent pathway). ARP, actin-related protein; CIN85, CBL-interacting protein of 85 kDa; DAG, diacylglycerol; Ig, immunoglobulin; I $\mathrm{KB}$, inhibitor of $\kappa B$; IKK, inhibitor of NF- $\kappa B$ kinase; IP3, inositol trisphosphate; IP3R, IP3 receptor; ITAM, immunoreceptor tyrosine-based activation motif; LBP, lipopolysaccharide-binding protein;MALT1, mucosa-associated lymphoid tissue lymphoma translocation protein 1; P, phosphorylation; PIP3, phosphatidylinositol3,4,5,-trisphosphate; PKC, protein kinase C; PLC $\gamma 2$, phospholipase C $\gamma 2$; SLP65, SH2 domain-containing leukocyte protein of $65 \mathrm{kDa}$; SYK, spleen tyrosine kinase; TAB, TGF $\beta$-activated kinase 1 and MAP3K7-binding protein; TAK1, TGF $\beta$-activated kinase 1; TRAF, TNF receptor-associated factor; WASP, Wiskott-Aldrich syndrome protein.

Waldenström's macroglobulinaemia (WM). An uncommon B cell malignancy with heterogeneous clinical presentation that is characterized by high levels of monoclonal immunoglobulin $\mathrm{M}$, secreted by lymphoplasmacytic lymphoma cells with bone marrow infiltration.

Multiple myeloma (Also known as Kahler's disease). A malignancy of plasma cells that accumulate in the bone marrow. In contrast to resting healthy human plasma cells, multiple myeloma cells show a low rate of proliferation, which results from cell cycle deregulation. because gene expression profiling of WM samples showed aberrant BCR signalling, including increased CD79B expression $^{119}$, and because WM cells depend on CXCR4 signalling for homing to the bone marrow ${ }^{120}$.

Multiple myeloma. Multiple myeloma cells originate from plasma cells that no longer express a BCR on their cell surface. For survival and proliferation, multiple myeloma cells seem to rely on signals that are produced as a result of increased osteoclastic activity and bone remodelling ${ }^{121,122}$. Bone marrow stromal cells, osteoclasts and osteoblasts give crucial activation and homing signals to multiple myeloma cells, such as a proliferation inducing ligand (APRIL; also known as TNFSF13) ${ }^{123}$, IL-6 and CXCL12 (REF. 124); therefore, therapies are being developed that interfere with the pro-survival signals that are derived from this bone marrow niche ${ }^{125}$.

In mice, BTK and TEC are indispensable for osteoclast formation, which is induced by receptor activator of NF- $\mathrm{kB}$ ligand (RANKL; also known as TNFSF11) ${ }^{126,127}$.
In line with this observation, ibrutinib blocked RANKLinduced phosphorylation of BTK and downstream PLC $\gamma 2$, and inhibited human osteoclast function in vitro, as measured by bone resorption activity. In osteoclasts or bone marrow stromal cells from patients with multiple myeloma, ibrutinib downregulated the production of tumour-supporting factors ${ }^{128}$, including CCL3, transforming growth factor- $\beta$, APRIL and CXCL12. Ibrutinib blocked CXCL12-induced adhesion and migration of multiple myeloma cells and reduced multiple myeloma cell growth and survival that was triggered by IL-6 (REF. 128). In vivo ibrutinib treatment in a mouse multiple myeloma transplantation model strongly abrogated tumour progression. Because ibrutinib also suppressed the potential of multiple myeloma stem-like cells to form colonies in vitro, it is conceivable that this drug might also disrupt BTK signalling in multiple myeloma cells ${ }^{128}$. BTK inhibition in multiple myeloma cells might also block additional pathways involved in disease progression, as TLR signalling in multiple myeloma might 


\section{Table 2 | The role of Bruton's tyrosine kinase in B cell malignancies}

\begin{tabular}{|c|c|c|c|c|}
\hline Malignancy & Incidence & $\begin{array}{l}\text { Presumed B cell of } \\
\text { origin }\end{array}$ & $\begin{array}{l}\text { Evidence for a role of BCR or TLR } \\
\text { signalling }\end{array}$ & Effects of BTK inhibition \\
\hline CLL & $\begin{array}{l}4.2 \text { per } 100,000 \\
\text { per year }\end{array}$ & $\begin{array}{l}\text { - U-CLL: germinal } \\
\text { centre-independent } \\
\text { mature CD5 }{ }^{+} \text {B cell } \\
\text { (lgM+; low SHM) } \\
\text { M-CLL: post-germinal } \\
\text { centre memory } \\
\text { CD5 }^{+} \text {CD } 27^{+} \text {B cell } \\
\text { (lgM+' high SHM) }\end{array}$ & $\begin{array}{l}\text { - Poor prognosis for ZAP70+CLL and } \\
\text { U-CLL, versus M-CLL } \\
\text { - Stereotypical BCRs } \\
\text { - BCR with known antigens } \\
\text { (and autoantigens) } \\
\text { - Increased basal Ca } a^{2+} \text { influx; MYD } 88^{2265 P} \\
\text { mutation in } \sim 3 \% \text { of cases }\end{array}$ & $\begin{array}{l}\text { - In vitro: inhibition of CXCL12-mediated } \\
\text { and CXCL13-mediated migration; } \\
\text { BCR-induced VCAM1-mediated } \\
\text { adhesion; reduced CLL viability } \\
\text { - In vivo: lymphocytosis; decline in the } \\
\text { concentration of CCL3 and CCL4 in the } \\
\text { serum }\end{array}$ \\
\hline $\mathrm{MCL}$ & $\begin{array}{l}4-8 \text { per } 1,000,000 \\
\text { per year }(\sim 6 \% \text { of } \\
\text { NHL cases) }\end{array}$ & $\begin{array}{l}\text { - Pre-germinal centre } \\
\text { mature CD5 } 5^{+} \text {B cell } \\
\text { - IgM }{ }^{+} \text {with low SHM } \\
\text { - A small proportion } \\
\text { carry BCRs with SHM }\end{array}$ & $\begin{array}{l}\text { - Biased and stereotypical BCRs } \\
\text { - Phosphorylation signature of BCR } \\
\text { signalling molecules } \\
\text { - SYK amplification }\end{array}$ & $\begin{array}{l}\text { - In vitro: inhibition of phosphorylation } \\
\text { of the BCR-downstream molecules } \\
\text { PLC } 22, \text { AKT, ERK and JNK; inhibition } \\
\text { of CXCL12- and CXCL13-mediated } \\
\text { migration and adhesion } \\
\text { - In vivo: lymphocytosis }\end{array}$ \\
\hline WM & $\begin{array}{l}\sim 0.3 \text { per } 100,000 \\
\text { per year }(\sim 2 \% \text { of } \\
\text { NHL cases })\end{array}$ & $\begin{array}{l}\text { - Post-germinal centre } \\
\text { B cell } \\
\text { - IgM+ with high levels } \\
\text { of SHM }\end{array}$ & $\begin{array}{l}\text { - Limited evidence for a role of BCR } \\
\text { signalling } \\
\text { - MYD88 } 8^{\text {L265P }} \text { mutation in }>90 \% \text { of cases }\end{array}$ & $\begin{array}{l}\text { Shown in WM cell lines: } \\
\text { - Inhibition of MYD88-BTK association } \\
\text { - Reduction of NF- } \kappa \text { B activation } \\
\text { - Induction of apoptosis }\end{array}$ \\
\hline $\begin{array}{l}\text { Multiple } \\
\text { myeloma }\end{array}$ & $\begin{array}{l}\sim 5.6 \text { per } 100,000 \\
\text { per year }\end{array}$ & $\begin{array}{l}\text { Long-lived } \\
\text { post-germinal centre } \\
\text { plasma cell, which is } \\
\text { class switched, with high } \\
\text { levels of SHM }\end{array}$ & $\mathrm{BCR}$ is not expressed on the cell surface & $\begin{array}{l}\text { - A reduction in the concentration } \\
\text { of CCL3 and APRIL in bone marrow } \\
\text { stromal cells and osteoclasts } \\
\text { - Inhibition of CXCL12-induced } \\
\text { adhesion and migration in multiple } \\
\text { myeloma cells } \\
\text { - Reduced IL-6-driven proliferation and } \\
\text { survival of multiple myeloma cells }\end{array}$ \\
\hline
\end{tabular}

increase disease progression ${ }^{129}$ and mutations in many genes that are involved in NF- $\kappa$ B signalling ${ }^{130-132}$ have been identified in multiple myeloma.

\section{BTK inhibitors in clinical trials}

In a Phase I open-label study of 56 patients with refractory or relapsed B cell malignancies (including CLL, small lymphocytic lymphoma (SLL), MCL, DLBCL, WM and follicular lymphoma) who failed at least one previous therapy, the safety and tolerability of ibrutinib (TABLE 1) was assessed ${ }^{133}$. Adverse events were mostly limited to grade 1 or 2 in severity, and grade 3 or 4 events were mostly haematological, including neutropenia, thrombocytopenia and anaemia. Pneumonia and bacteraemia were also among the most frequent severe adverse events reported in ibrutinib-treated patients with CLL or SLL ${ }^{19}$. Six patients discontinued study participation because of adverse events. Thus, ibrutinib is mostly well tolerated and safe.

None of the 14 patients with CLL or SLL included in this Phase I study showed progressive disease, and the overall response rate (ORR) was $79 \%{ }^{133}$. In a follow-up Phase II study, 85 patients with refractory or relapsed CLL or SLL received continuous ibrutinib treatment ${ }^{19}$.
An ORR of $71 \%$ was reported, without significant differences between subgroups. Ibrutinib caused a transient increase in blood lymphocyte levels, concurrent with a reduction in lymph node or spleen size. This asymptomatic lymphocytosis is explained by the role of BTK in chemokine receptor signalling. Approximately $77 \%$ of patients with U-CLL and only $~ 33 \%$ of patients with M-CLL showed a response, but this difference was due to a more rapid and more frequent resolution of lymphocytosis in patients with U-CLL. Another $~ 42 \%$ of patients with M-CLL showed a partial response with lymphocytosis, and if these patients were included, the ORR of patients with M-CLL and patients with U-CLL was not different. Similar results were obtained in an open-label Phase IB/II trial in 31 previously untreated patients with CLL or SLL ${ }^{134}$. Moreover, progression-free survival was not reduced in patients with prolonged lymphocytosis during ibrutinib therapy, which indicates that persistent lymphocytosis does not signify a suboptimal response to ibruti$\mathrm{nib}^{135}$. The estimated progression-free survival and ORR at 26 months in the Phase II study ${ }^{19}$ were $75 \%$ and 83\%, respectively, which indicates that ibrutinib is efficacious in heavily pretreated patients with CLL or SLL. 
These findings have encouraged the initiation of additional clinical studies to assess the effectiveness of other BTK inhibitors in patients with CLL and SLL (TABLE 1). Moreover, interim analyses of ibrutinib in combination regimens show good ORRs ${ }^{136,137}$. It is expected that a substantial proportion of patients will reach long-term progression-free survival with ibrutinib, but specific subgroups may experience relatively early relapses: that is, patients with deletions of $11 \mathrm{q}$ or $17 \mathrm{p}^{19}$ who, owing to genomic instability, might be highly likely to acquire resistance mutations ${ }^{138}$. The presence of $\mathrm{BTK}^{\mathrm{C} 481 \mathrm{~s}}$ and $\mathrm{PLC} \gamma 2^{\mathrm{R} 665 \mathrm{~W}}$ mutations in patients treated with ibrutinib indicates possible mechanisms of ibrutinib resistance, although the rates of the occurrence of these mutations might be low, as few cases have been documented so far ${ }^{138}$.

In the ibrutinib Phase I study ${ }^{133}$, seven of the nine patients with MCL responded to treatment. In a subsequent Phase II study in which 111 patients with refractory or relapsed MCL were treated, an impressive ORR of $\sim 68 \%$ (including $21 \%$ complete responses) was reported ${ }^{20}$. Paralleling the Phase II study in CLL ${ }^{19}$, the response to ibrutinib treatment was independent of disease severity, risk factors and patient characteristics ${ }^{20}$. Interestingly, recent transcriptome sequencing showed that insensitivity to ibrutinib is associated with activation of the alternative NF- $\kappa B$ pathway and mutations in TNF receptor-associated factor 2 (TRAF2) and baculoviral IAP repeat-containing 3 (BIRC3), in contrast to the chronic activation of the BCRdriven classical NF- $\kappa \mathrm{B}$ pathway that is found in highly ibrutinib-sensitive MCL lines ${ }^{139}$.

Although grade 3 or grade 4 adverse events were infrequently seen, two patients died of pneumonia and one patient died of bacterial sepsis in this trial ${ }^{20}$. The recurrence of bacterial complications in both Phase II trials may, to some extent, mimic the XLA phenotype (BOX 1), but there is no evidence that ibrutinib treatment is associated with infection due to blockade of BTK signalling in functional B cells. Serum IgM, IgG and IgA levels did not decrease during treatment ${ }^{19,20,134}$, and increased susceptibility to infection is one of the characteristics of the clinical course of B cell malignancies.

In a Phase I study ${ }^{133}$, two of the seven patients with DLBCL had a partial response. The lower ORR in DLBCL compared with CLL and MCL might be attributed to differences in the BTK dependency of DLBCL subtypes ${ }^{18}$. Indeed, interim results of a Phase II study showed that ibrutinib treatment induced an ORR of $\sim 41 \%$ and $~ 5 \%$ in $\mathrm{ABC}$-DLBCL and germinal centre-DLBCL, respectively ${ }^{140}$. Importantly, ibrutinib also induced responses in patients carrying mutant CD79B or MYD88 alleles, which indicates that BTK inhibition can override pathogenic constitutive signalling of these molecules. Clinical trials addressing the effectiveness of different BTK inhibitors in DLBCL are currently ongoing (TABLE 1).

The finding that three of the four patients with refractory or relapsed WM showed a partial response in the Phase I study ${ }^{133}$ prompted further investigation of BTK inhibition in WM. Recent interim results of a Phase II trial with ibrutinib showed an ORR of $\sim 83 \%$ and markedly reduced serum IgM levels in patients ${ }^{141}$. Likewise, in an ongoing Phase II trial of ibrutinib treatment in refractory or relapsed multiple myeloma, reduced values for various markers in the blood were reported ${ }^{142}$. These markers included RANKL and CCL3, which indicates that ibrutinib has a biological effect on the microenvironment in multiple myeloma.

\section{Perspectives}

Targeting BTK function shows promise as a therapy for various B cell malignancies: BTK inhibition is mostly well tolerated, and ibrutinib induced a durable objective response in many patients. Numerous Phase II and Phase III clinical trials are currently ongoing to evaluate BTK inhibition in patients with CLL, MCL, DLBCL, WM and multiple myeloma (TABLE 1). Moreover, it will be interesting to investigate BTK inhibition in several other B cell malignancies, such as splenic marginal zone lymphoma, in which mutations in MYD88 and components of the NF- $\kappa B$ pathway have recently been found ${ }^{143}$, and follicular lymphoma, in which BCR antigen (and autoantigen) recognition has been implicated in survival $^{144}$. In this context, it is of note that the incidence of DLBCL and marginal zone lymphoma is increased in patients with systemic autoimmune disease ${ }^{145}$, in which BTK activation is thought to be a key pathogenic event and for which preclinical models show strong in vivo effects of BTK inhibition ${ }^{17,146-149}$. The recent finding of a novel BTK isoform that protects breast cancer cells from apoptosis ${ }^{150}$ should prompt analyses of BTK expression in other tumours, as well as experiments that address how BTK becomes involved in epithelial cell signal transduction pathways.

Much progress has been made in recent years in defining the mechanisms of action of BTK inhibitors. BTK is involved in different pathological mechanisms, and it now seems likely that in many cases the effects of BTK inhibition on tumour progression are a result of a complex interplay of signals that are derived from various receptors on B cells and responses to microenvironmental stimuli. Therefore, novel insights into the oncogenic role of BTK signalling in the context of genomic aberrations in malignancies are crucial to optimize the use of BTK-targeting therapeutics. Development, as well as clinical and preclinical investigation, of BTK inhibitors with greater or different specificity might be beneficial for patient groups that do not show a significant response to ibrutinib. In some cases, it may be advantageous to use BTK inhibitors that show additional specificity for related kinases, as exemplified by the synergy between BTK and TEC in osteoclast function in multiple myeloma cells. More studies are needed to learn which patients benefit the most from which specific compound. In this context, the application of new technology, including transcriptome analysis by next-generation sequencing, will be beneficial. High-throughput combinatorial screening strategies should help to identify ibrutinib combinations that can be prioritized for clinical investigation ${ }^{151}$. Such combination regimens are expected to result in long-lasting responses by preventing the development of resistance to BTK inhibition and avoiding lifelong treatment with inhibitors. 
1. Vetrie, $\mathrm{D}$, et al. The gene involved in X-linked agammaglobulinaemia is a member of the src family of protein-tyrosine kinases. Nature 361, 226-233 (1993).

2. Tsukada, S. et al. Deficient expression of a B cell cytoplasmic tyrosine kinase in human X-linked agammaglobulinemia. Cell 72, 279-290 (1993).

3. Hendriks, R. W., Bredius, R. G., Pike-Overzet, K. \& Staal, F. J. Biology and novel treatment options for $\mathrm{XLA}$, the most common monogenetic immunodeficiency in man. Expert Opin. Ther. Targets 15, 1003-1021 (2011)

4. Conley, M. E., Parolini, O., Rohrer, J. \& Campana, D. $X$-linked agammaglobulinemia: new approaches to old questions based on the identification of the defective gene. Immunol. Rev. 138, 5-21 (1994).

5. Rawlings, D. J. et al. Mutation of unique region of Bruton's tyrosine kinase in immunodeficient XID mice. Science 261, 358-361 (1993).

6. Thomas, J. D. et al. Colocalization of X-linked agammaglobulinemia and X-linked immunodeficiency genes. Science 261, 355-358 (1993).

7. Aoki, Y., Isselbacher, K. J. \& Pillai, S. Bruton tyrosine kinase is tyrosine phosphorylated and activated in pre-B lymphocytes and receptor-ligated B cells. Proc. Natl Acad Sci. USA 91, 10606-10609 (1994).

8. de Weers, M. et al. B-cell antigen receptor stimulation activates the human Bruton's tyrosine kinase, which is deficient in X-linked agammaglobulinemia. J. Biol. Chem. 269, 23857-23860 (1994).

9. Saouaf, S. J. et al. Temporal differences in the activation of three classes of non-transmembrane protein tyrosine kinases following B-cell antigen receptor surface engagement. Proc. Natl Acad. Sci. USA 91, 9524-9528 (1994).

10. Khan, W. N. et al. Defective B cell development and function in Btk-deficient mice. Immunity 3, 283-299 (1995).

11. Brorson, K. et al. xid affects events leading to $B$ cell cycle entry. J. Immunol. 159, 135-143 (1997).

12. Solvason, N. et al. Transgene expression of bcl-xL permits anti-immunoglobulin (Ig)-induced proliferation in xid B cells. J. Exp. Med. 187, 1081-1091 (1998).

13. Hendriks, R. W. \& Middendorp, S. The pre-BCR checkpoint as a cell-autonomous proliferation switch. Trends Immunol. 25, 249-256 (2004).

14. de Weers, M. et al. The Bruton's tyrosine kinase gene is expressed throughout $B$ cell differentiation, from early precursor $\mathrm{B}$ cell stages preceding immunoglobulin gene rearrangement up to mature B cell stages. Eur. J. Immunol. 23, 3109-3114 (1993).

15. Katz, F. E. et al. Expression of the X-linked agammaglobulinemia gene, btk in B-cell acute lymphoblastic leukemia. Leukemia 8, 574-577 (1994).

16. Mahajan, S. et al. Rational design and synthesis of a novel anti-leukemic agent targeting Bruton's tyrosine kinase (BTK), LFM-A13 [ $\alpha$-cyano- $\beta$-hydroxy- $\beta$ methyl-N-(2, 5-dibromophenyl)propenamide]. J. Biol. Chem. 274, 9587-9599 (1999).

17. Honigberg, L. A. et al. The Bruton tyrosine kinase inhibitor $\mathrm{PCl}-32765$ blocks B-cell activation and is efficacious in models of autoimmune disease and B-cell malignancy. Proc. Natl Acad. Sci. USA 107 13075-13080 (2010).

This is the first description of ibrutinib, and it supports BTK inhibition as a therapeutic approach for the treatment of $B$ cell malignancies.

18. Davis, R. E. et al. Chronic active B-cell-receptor signalling in diffuse large B-cell lymphoma. Nature 463, 88-92 (2010)

This paper establishes chronic activation of BCR signalling as a new pathogenetic mechanism in $A B C-D L B C L$, and it shows the essential role of BTK in DLBCL.

19. Byrd, J. C. et al. Targeting BTK with ibrutinib in relapsed chronic lymphocytic leukemia. $N$. Engl. J. Med. 369, 32-42 (2013)

20. Wang, M. L. et al. Targeting BTK with ibrutinib in relapsed or refractory mantle-cell lymphoma. N. Engl. J. Med. 369, 507-516 (2013).

References 19 and 20 report the outcome of Phase II studies showing that BTK inhibition was associated with a high response rate in patients with CLL and MCL.

21. Smith, C. I. et al. Expression of Bruton's agammaglobulinemia tyrosine kinase gene, $B T K$, is selectively down-regulated in T lymphocytes and plasma cells. J. Immunol. 152, 557-565 (1994).
22. Bradshaw, J. M. The Src, Syk, and Tec family kinases: distinct types of molecular switches. Cell Signal 22, 1175-1184 (2010)

23. Hyvonen, M. $\&$ Saraste, M. Structure of the PH domain and Btk motif from Bruton's tyrosine kinase: molecular explanations for X-linked agammaglobulinaemia. EMBO J. 16, 3396-3404 (1997).

24. Park, H. et al. Regulation of Btk function by a major autophosphorylation site within the $\mathrm{SH} 3$ domain. Immunity 4, 515-525 (1996)

25. Rawlings, D. J. et al. Activation of BTK by a phosphorylation mechanism initiated by SRC family kinases. Science 271, 822-825 (1996).

26. Li, T. et al. Activation of Bruton's tyrosine kinase (BTK) by a point mutation in its pleckstrin homology $(\mathrm{PH})$ domain. Immunity 2, 451-460 (1995).

27. Dingjan, G. M. et al. Severe B cell deficiency and disrupted splenic architecture in transgenic mice expressing the $\mathrm{E} 41 \mathrm{~K}$ mutated form of Bruton's tyrosine kinase. EMBO J. 17, 5309-5320 (1998).

28. Valiaho, J., Smith C. I. \& Vihinen, M. BTKbase: the mutation database for X-linked agammaglobulinemia. Hum. Mutat. 27, 1209-1217 (2006).

29. Middendorp, S., Dingjan, G. M., Maas, A

Dahlenborg, K. \& Hendriks, R. W. Function of Bruton's tyrosine kinase during $B$ cell development is partially independent of its catalytic activity. J. Immunol. 171 5988-5996 (2003)

30. Gustafsson, M. O. et al. Regulation of nucleocytoplasmic shuttling of Bruton's tyrosine kinase (Btk) through a novel SH3-dependent interaction with ankyrin repeat domain 54 (ANKRD54). Mol. Cell. Biol. 32, 2440-2453 (2012).

31. Hirano, M. et al. Bruton's tyrosine kinase (Btk) enhances transcriptional co-activation activity of BAM11, a Btk-associated molecule of a subunit of SWI SNF complexes. Int. Immunol. 16, 747-757 (2004).

32. Rajaiya, J. et al. Induction of immunoglobulin heavychain transcription through the transcription factor Bright requires TFII-I. Mol. Cell. Biol. 26, 4758-4768 (2006)

33. Nisitani, S. et al. Posttranscriptional regulation of Bruton's tyrosine kinase expression in antigen receptor-stimulated splenic B cells. Proc. Natl Acad. Sci. USA 97, 2737-2742 (2000)

34. Belver, L., de Yebenes, V. G. \& Ramiro, A. R. MicroRNAs prevent the generation of autoreactive antibodies. Immunity 33, 713-722 (2010).

35. Yu, L. et al. Proteasome-dependent autoregulation of Bruton tyrosine kinase (Btk) promoter via NF- $\mathrm{kB}$ Blood 111, 4617-4626 (2008)

36. Satterthwaite, A. B., Cheroutre, H., Khan, W. N., Sideras, P. \& Witte, O. N. Btk dosage determines sensitivity to $B$ cell antigen receptor cross-linking. Proc. Natl Acad. Sci. USA 94, 13152-13157 (1997).

37. Drabek, D et al. Correction of the X-linked immunodeficiency phenotype by transgenic expression of human Bruton tyrosine kinase under the control of the class II major histocompatibility complex Ea locus control region. Proc. Natl Acad. Sci. USA 94 , 610-615 (1997).

38. Kil, L. P. et al. Btk levels set the threshold for B-cell activation and negative selection of autoreactive B cells in mice. Blood 119, 3744-3756 (2012)

39. Kil, L. P. et al. Bruton's tyrosine kinase mediated signaling enhances leukemogenesis in a mouse model for chronic lymphocytic leukemia. Am. J. Blood Res. 3 , 71-83 (2013)

40. Rolli, V. et al. Amplification of B cell antigen receptor signaling by a Syk/ITAM positive feedback loop. $\mathrm{Mol}$. Cell 10, 1057-1069 (2002).

41. O'Rourke, L. M. et al. CD19 as a membrane-anchored adaptor protein of B lymphocytes: costimulation of lipid and protein kinases by recruitment of Vav. Immunity 8, 635-645 (1998).

42. Inabe, K. et al. Vav3 modulates B cell receptor responses by regulating phosphoinositide 3-kinas activation. J. Exp. Med. 195, 189-200 (2002).

43. Okada, T Maeda, A Iwamatsu, A Gotoh, K \& Kurosaki, T. BCAP: the tyrosine kinase substrate that connects B cell receptor to phosphoinositide 3-kinase activation. Immunity 13, 817-827 (2000)

44. Saito, K., Scharenberg, A. M. \& Kinet, J. P. Interaction between the Btk PH domain and phosphatidylinositol-3,4,5-trisphosphate directly regulates Btk. J. Biol. Chem. 276, 16201-16206 (2001)

45. Kurosaki, T. \& Kurosaki, M. Transphosphorylation of Bruton's tyrosine kinase on tyrosine 551 is critical for B cell antigen receptor function. J. Biol. Chem. 272 15595-15598 (1997).
46. Fu, C., Turck, C. W., Kurosaki, T. \& Chan, A. C. BLNK: central linker protein in B cell activation. Immunity 9 , 93-103 (1998).

47. Oellerich, T. et al. The B-cell antigen receptor signals through a preformed transducer module of SLP65 and CIN85. EMBO J. 30, 3620-3634 (2011)

48. Weber, M. et al. Phospholipase C- $\gamma 2$ and Vav cooperate within signaling microclusters to propagate $B$ cell spreading in response to membrane-bound antigen. J. Exp. Med. 205, 853-868 (2008).

49. Kim, Y. J., Sekiya, F. Poulin, B., Bae, Y. S. \& Rhee, S. C. Mechanism of B-cell receptor-induced phosphorylation and activation of phospholipase C- $\gamma 2$. Mol. Cell. Biol. 24, 9986-9999 (2004)

50. Saito, K. et al. BTK regulates Ptdlns-4, 5-P2 synthesis: importance for calcium signaling and PI3K activity. Immunity 19, 669-678 (2003).

51. Hashimoto, A. et al. Involvement of guanosine triphosphatases and phospholipase $\mathrm{C}-\gamma 2$ in extracellular signal-regulated kinase, c-Jun $\mathrm{NH} 2$-terminal kinase, and p38 mitogen-activated protein kinase activation by the B cell antigen receptor. J. Exp. Med. 188, 1287-1295 (1998)

52. Shinohara, H., Maeda, S., Watarai, H. \& Kurosaki, T. IкB kinase $\beta$-induced phosphorylation of CARMA contributes to CARMA1 Bcl10 MALT1 complex formation in B cells. J. Exp. Med. 204, 3285-3293 (2007).

53. Petro, J. B., Rahman, S. M., Ballard, D. W. \& Khan, W. N. Bruton's tyrosine kinase is required for activation of $\mathrm{I} \mathrm{K} B$ kinase and nuclear factor $\mathrm{\kappa B}$ in response to $\mathrm{B}$ cell receptor engagement. J. Exp. Med. 191, 1745-1754 (2000)

54. Bajpai, U. D., Zhang, K., Teutsch, M., Sen, R. \& Wortis, H. H. Bruton's tyrosine kinase links the B cell receptor to nuclear factor $\mathrm{\kappa B}$ activation. J. Exp. Med. 191, 1735-1744 (2000)

55. Sharma, S., Orlowski, G. ¿ Song, W. Btk regulates $B$ cell receptor-mediated antigen processing and presentation by controlling actin cytoskeleton dynamics in B cells. J. Immunol. 182, 329-339 (2009).

56. Nore, B. F. et al. Redistribution of Bruton's tyrosine kinase by activation of phosphatidylinositol 3-kinase and Rho-family GTPases. Eur. J. Immunol. 30 , 145-154 (2000)

57. Yao, L. et al. Pleckstrin homology domains interact with filamentous actin. J. Biol. Chem. 274 19752-19761 (1999).

58. Kuehn, H. S. et al. Btk-dependent Rac activation and actin rearrangement following FceRI aggregation promotes enhanced chemotactic responses of mast cells. J. Cell Sci. 123, 2576-2585 (2010).

59. Spaargaren, M. et al. The B cell antigen receptor controls integrin activity through Btk and PLC 22 J. Exp. Med. 198, 1539-1550 (2003).

60. Koopman, G. et al. Adhesion through the LFA-1 (CD11a/CD 18)-ICAM-1 (CD54) and the VLA-4 (CD49d)-VCAM-1 (CD106) pathways prevents apoptosis of germinal center B cells. J. Immunol. 152, 3760-3767 (1994).

61. Guo, B., Kato, R. M., Garcia-Lloret, M., Wahl, M. I. \& Rawlings, D. J. Engagement of the human pre-B cell receptor generates a lipid raft-dependent calcium signaling complex. Immunity 13, 243-253 (2000).

62. Pede, V. et al. Expression of ZAP70 in chronic lymphocytic leukaemia activates NF-kB signalling. $\mathrm{Br}$. J. Haematol. 163, 621-630 (2013).

63. Ubelhart, R. et al. N-linked glycosylation selectively regulates autonomous precursor BCR function. Nature Immunol. 11, 759-765 (2010).

64. Gauthier, L., Rossi, B., Roux, F., Termine, E. \& Schiff, C. Galectin-1 is a stromal cell ligand of the pre-B cell receptor (BCR) implicated in synapse formation between pre-B and stromal cells and in pre-BCR triggering. Proc. Natl Acad. Sci. USA 99 13014-13019 (2002).

65. Bradl, H., Wittmann, J., Milius, D., Vettermann, C. $\varnothing$ Jack, H. M. Interaction of murine precursor B cell receptor with stroma cells is controlled by the unique tail of $\lambda 5$ and stroma cell-associated heparan sulfate. J. Immunol. 171, 2338-2348 (2003).

66. Flemming, A., Brummer, T., Reth, M. \& Jumaa, H. The adaptor protein SLP-65 acts as a tumor suppressor that limits pre-B cell expansion. Nature Immunol. 4 38-43 (2003)

67. van Loo, P. F., Dingjan, G. M., Maas, A. \& Hendriks, R. W. Surrogate-light-chain silencing is not critical for the limitation of pre-B cell expansion but is for the termination of constitutive signaling. Immunity 27, 468-480 (2007) 
68. Nakayama, J. et al. BLNK suppresses pre-B-cell leukemogenesis through inhibition of JAK3. Blood 113, 1483-1492 (2009)

69. Kersseboom, R. et al. Bruton's tyrosine kinase cooperates with the B cell linker protein SLP-65 as a tumor suppressor in Pre-B cells. J. Exp. Med. 198 91-98 (2003).

70. Middendorp, S. et al. Tumor suppressor function of Bruton tyrosine kinase is independent of its catalytic activity. Blood 105, 259-265 (2005).

71. Jumaa, H. et al. Deficiency of the adaptor SLP-65 in pre-B-cell acute lymphoblastic leukaemia. Nature 423, 452-456 (2003)

72. Goodman, P. A., Wood, C. M., Vassilev, A. O., Mao, C \& Uckun, F. M. Defective expression of Bruton's tyrosine kinase in acute lymphoblastic leukemia. Leuk. Lymphoma 44, 1011-1018 (2003).

73. Feldhahn, N. et al. Deficiency of Bruton's tyrosine kinase in B cell precursor leukemia cells. Proc. Natl Acad. Sci. USA 102, 13266-13271 (2005).

74. de Gorter, D. J. et al. Bruton's tyrosine kinase and phospholipase $C \gamma 2$ mediate chemokine-controlled $\mathrm{B}$ cell migration and homing. Immunity 26, 93-104 (2007).

This paper shows the involvement of BTK in chemokine receptor signalling.

75. Tsukada, S., Simon, M. I., Witte, O. N. \& Katz, A. Binding of $\beta \gamma$ subunits of heterotrimeric $G$ proteins to the PH domain of Bruton tyrosine kinase. Proc. NatI Acad. Sci. USA 91, 11256-11260 (1994).

76. Jiang, Y. et al. The $\mathrm{G}$ protein $\mathrm{G} \alpha 12$ stimulates Bruton's tyrosine kinase and a rasGAP through a conserved PH/BM domain. Nature 395, 808-813 (1998).

77. Lowry, W. E. \& Huang, X. Y. G. Protein $\beta \gamma$ subunits act on the catalytic domain to stimulate Bruton's agammaglobulinemia tyrosine kinase. J. Biol. Chem 277, 1488-1492 (2002)

78. de Rooij, M. F. et al. The clinically active BTK inhibitor $\mathrm{PCl}-32765$ targets B-cell receptor- and chemokinecontrolled adhesion and migration in chronic lymphocytic leukemia. Blood 119, 2590-2594 (2012).

79. Chang, B. Y. et al. Egress of $\mathrm{CD} 19+\mathrm{CD} 5+$ cells into peripheral blood following treatment with the BTK inhibitor ibrutinib in mantle cell lymphoma patients. Blood 122, 2412-2424 (2013).

80. Ponader, S. et al. The Bruton tyrosine kinase inhibitor $\mathrm{PCl}-32765$ thwarts chronic lymphocytic leukemia cell survival and tissue homing in vitro and in vivo. Blood 119, 1182-1189 (2012)

81. Rawlings, D. J., Schwartz, M. A., Jackson, S. W. \& Meyer-Bahlburg, A. Integration of B cell responses through Toll-like receptors and antigen receptors. Nature Rev. Immunol. 12, 282-294 (2012).

82. Jefferies, C. A. et al. Bruton's tyrosine kinase is a Toll/ interleukin-1 receptor domain-binding protein that participates in nuclear factor $\mathrm{kB}$ activation by Toll-like receptor 4. J. Biol. Chem. 278 26258-26264 (2003)

83. Liu, X. et al. Intracellular MHC class II molecules promote TLR-triggered innate immune responses by maintaining activation of the kinase Btk. Nature Immunol. 12, 416-424 (2011).

84. Lee, K. G. et al. Bruton's tyrosine kinase phosphorylates Toll-like receptor 3 to initiate antiviral response. Proc. Natl Acad. Sci. USA 109, 5791-5796 (2012).

85. Marron, T. U., Martinez-Gallo, M., Yu, J. E. \& Cunningham-Rundles, C. Toll-like receptor 4-, 7-, and 8-activated myeloid cells from patients with X-linked agammaglobulinemia produce enhanced inflammatory cytokines. J. Allergy Clin. Immunol. 129, 184-190 (2012).

86. Kenny, E. F et al. Bruton's tyrosine kinase mediates the synergistic signalling between TLR9 and the B cell receptor by regulating calcium and calmodulin. PLOS ONE 8, e74103 (2013).

87. Chaturvedi, A., Dorward, D. \& Pierce, S. K. The B cell receptor governs the subcellular location of Toll-like receptor 9 leading to hyperresponses to DNA-containing antigens. Immunity 28, 799-809 (2008).

88. Muzio, M. et al. Constitutive activation of distinct BCR-signaling pathways in a subset of CLL patients: a molecular signature of anergy. Blood 112, 188-195 (2008).

89. Mockridge, C. I. et al. Reversible anergy of slgMmediated signaling in the two subsets of CLL defined by VH-gene mutational status. Blood 109 , 4424-4431 (2007).
90. Herishanu, Y. et al. The lymph node microenvironment promotes B-cell receptor signaling, NF-kB activation, and tumor proliferation in chronic lymphocytic leukemia. Blood 117, 563-574 (2011).

91. Hoogeboom, R. et al. A mutated B cell chronic lymphocytic leukemia subset that recognizes and responds to fungi. J. Exp. Med. 210, 59-70 (2013).

92. Kil, L. P., Yuvaraj, S., Langerak, A. W. \& Hendriks, R. W. The role of B cell receptor stimulation in CLL pathogenesis. Curr. Pharm. Des. 18 3335-3355 (2012)

93. Duhren-von Minden, M. et al. Chronic lymphocytic leukaemia is driven by antigen-independent cellautonomous signalling. Nature 489, 309-312 (2012).

94. Herman, S. E. et al. Bruton tyrosine kinase represents a promising therapeutic target for treatment of chronic lymphocytic leukemia and is effectively targeted by PCl-32765. Blood 117, 6287-6296 (2011).

95. ter Brugge, P. J. et al. A mouse model for chronic lymphocytic leukemia based on expression of the SV40 large T antigen. Blood 114, 119-127 (2009).

96. Dubovsky, J. A. et al. Lymphocyte cytosolic protein 1 is a chronic lymphocytic leukemia membraneassociated antigen critical to niche homing. Blood 122, 3308-3316 (2013)

97. Hoogeboom, R. et al. A novel chronic lymphocytic leukemia subset expressing mutated IGHV3-7-encoded rheumatoid factor B-cell receptor that are functionally proficient. Leukemia $\mathbf{2 7}$ 738-740 (2013).

98. Sivina, M. et al. CCL3 (MIP-1 $\alpha$ ) plasma levels and the risk for disease progression in chronic lymphocytic leukemia. Blood 117, 1662-1669 (2011).

99. Hadzidimitriou, A. et al. Is there a role for antigen selection in mantle cell lymphoma? Immunogenetic support from a series of 807 cases. Blood 118, 3088-3095 (2011)

100. Pighi, C. et al. Phospho-proteomic analysis of mantle cell lymphoma cells suggests a pro-survival role of B-cell receptor signaling. Cell Oncol. 34, 141-153 (2011).

101. Boyd, R. S. et al. Protein profiling of plasma membranes defines aberrant signaling pathways in mantle cell lymphoma. Mol. Cell Proteomics. 8, 1501-1515 (2009).

102. Rinaldi, A. et al. Genomic and expression profiling identifies the B-cell associated tyrosine kinase Syk as a possible therapeutic target in mantle cell lymphoma. Br. J. Haematol. 132, 303-316 (2006).

103. Jares, P., Colomer, D. \& Campo, E. Molecular pathogenesis of mantle cell lymphoma. J. Clin. Invest. 122, 3416-3423 (2012)

104. Cinar, M. et al. Bruton tyrosine kinase is commonly overexpressed in mantle cell lymphoma and its attenuation by Ibrutinib induces apoptosis. Leuk. Res. 37, 1271-1277 (2013).

105. Alizadeh, A. A. et al. Distinct types of diffuse large B-cell lymphoma identified by gene expression profiling. Nature 403, 503-511 (2000).

106. Davis, R. E., Brown, K. D., Siebenlist, U. Staudt, L. M. Constitutive nuclear factor $\kappa \mathrm{B}$ activity is required for survival of activated $B$ cell-like diffuse large B cell lymphoma cells. J. Exp. Med. 194 1861-1874 (2001).

107. Ngo, V. N. et al. A loss-of-function RNA interference screen for molecular targets in cancer. Nature 441 106-110 (2006).

108. Lenz, G. et al. Oncogenic CARD 11 mutations in human diffuse large B cell lymphoma. Science 319, 1676-1679 (2008)

109. Compagno, M. et al. Mutations of multiple genes cause deregulation of NF-kB in diffuse large B-cell lymphoma. Nature 459, 717-721 (2009).

110. Ngo, V. N. et al. Oncogenically active MYD88 mutations in human lymphoma. Nature $\mathbf{4 7 0}$ 115-119 (2011).

111. Monti, S. et al. Molecular profiling of diffuse large B-cell lymphoma identifies robust subtypes including one characterized by host inflammatory response. Blood 105, 1851-1861 (2005)

112. Chen, L. et al. SYK-dependent tonic B-cell receptor signaling is a rational treatment target in diffuse large B-cell lymphoma. Blood 111, 2230-2237 (2008).

113. Juszczynski, P. et al. BCL6 modulates tonic BCR signaling in diffuse large B-cell lymphomas by repressing the SYK phosphatase, PTPROt. Blood 114, 5315-5321 (2009).

114. Zhang, J. et al. Genetic heterogeneity of diffuse large B-cell lymphoma. Proc. Natl Acad. Sci. USA 110, 1398-1403 (2013)
115. Chen, L et al SYK inhibition modulates distinct PI3K AKT- dependent survival pathways and cholesterol biosynthesis in diffuse large B cell lymphomas. Cancer Cell 23, 826-838 (2013)

116. Hantschel, O. et al. The Btk tyrosine kinase is a majo target of the Bcr-Abl inhibitor dasatinib. Proc. Natl Acad. Sci. USA 104, 13283-13288 (2007).

117. Treon, S. P. et al. MYD88 L265P somatic mutation in Waldenstrom's macroglobulinemia. N. Engl. J. Med. 367, 826-833 (2012).

118. Yang, G. et al. A mutation in MYD88 (L265P) supports the survival of lymphoplasmacytic cells by activation of Bruton tyrosine kinase in Waldenstrom macroglobulinemia. Blood 122, 1222-1232 (2013).

119. Chng, W. J. et al. Gene-expression profiling of Waldenstrom macroglobulinemia reveals a phenotype more similar to chronic lymphocytic leukemia than multiple myeloma. Blood 108, 2755-2763 (2006).

120. Ngo, H. T. et al. SDF-1/CXCR4 and VLA-4 interaction regulates homing in Waldenstrom macroglobulinemia Blood 112, 150-158 (2008)

121. Kuehl, W. M. \& Bergsagel, P. L. Molecular pathogenesis of multiple myeloma and its premalignant precursor. J. Clin. Invest. 122, 3456-3463 (2012).

122. Raje, N. \& Roodman, G. D. Advances in the biology and treatment of bone disease in multiple myeloma. Clin. Cancer Res. 17, 1278-1286 (2011)

123. Abe, M. et al. BAFF and APRIL as osteoclast-derived survival factors for myeloma cells: a rationale for $\mathrm{TACl}-\mathrm{Fc}$ treatment in patients with multiple myeloma. Leukemia 20, 1313-1315 (2006).

124. Alsayed, Y. et al. Mechanisms of regulation of CXCR4/ SDF-1 (CXCL12)-dependent migration and homing in multiple myeloma. Blood 109, 2708-2717 (2007).

125. Hideshima, T., Mitsiades, C., Tonon, G., Richardson, P. G. \& Anderson, K. C. Understanding multiple myeloma pathogenesis in the bone marrow to identify new therapeutic targets. Nature Rev. Cancer 7, 585-598 (2007)

126. Shinohara, M. et al. Tyrosine kinases Btk and Tec regulate osteoclast differentiation by linking RANK and ITAM signals. Cell 132, 794-806 (2008).

127. Lee, S. H., Kim, T., Jeong, D., Kim, N. \& Choi, Y. The tec family tyrosine kinase Btk Regulates RANKLinduced osteoclast maturation. J. Biol. Chem. 283 11526-11534 (2008).

128. Tai, Y. T. et al. Bruton tyrosine kinase inhibition is a novel therapeutic strategy targeting tumor in the bone marrow microenvironment in multiple myeloma. Blood 120, 1877-1887 (2012)

This is the first description of a crucial role of BTK in the tumour microenvironment in the pathogenesis of a B cell malignancy.

129. Bao, H. et al. Triggering of toll-like receptor-4 in human multiple myeloma cells promotes proliferation and alters cell responses to immune and chemotherapy drug attack. Cancer Biol. Ther. 11, 58-67 (2011).

130. Chapman, M. A. et al. Initial genome sequencing and analysis of multiple myeloma. Nature 471, 467-472 (2011)

131. Keats, J. J. et al. Promiscuous mutations activate the noncanonical NF-kB pathway in multiple myeloma. Cancer Cell 12, 131-144 (2007).

132. Annunziata, C. M. et al. Frequent engagement of the classical and alternative NF-kB pathways by diverse genetic abnormalities in multiple myeloma. Cancer Cell 12, 115-130 (2007)

133. Advani, R. H. et al. Bruton tyrosine kinase inhibitor ibrutinib (PCl-32765) has significant activity in patients with relapsed/refractory B-cell malignancies. J. Clin. Oncol. 31, 88-94 (2013).

134. O'Brien, S. et al. Ibrutinib as initial therapy for elderly patients with chronic lymphocytic leukaemia or small lymphocytic lymphoma: an open-label, multicentre, phase 1b/2 trial. Lancet Oncol. 15, 48-58 (2014).

135. Woyach, J. A. et al. Prolonged lymphocytosis during ibrutinib therapy is associated with distinct molecular characteristics and does not indicate a suboptimal response to therapy. Blood http://dx.doi.org/10.1182 blood-2013-09-527853 (2014).

136. Burger, J. A., Wierda, W. G. $\&$ Hoellenriegel, J. The Btk inhibitor ibrutinib (PCl-32765) in combination with rituximab is well tolerated and displays profound activity in high-risk chronic lymphocytic leukemia (CLL) patients. Proc ASH Abstr. 187 (2012).

137. Brown, J. R. Combination of the Bruton's tyrosine kinase inhibitor $\mathrm{PCl}-32765$ with bendamustine/ rituximab (BR) in patients with relapsed/refractory chronic lymphocytic leukemia: Interim results of a phase lb/ll study. EHA Meeting 2012 Abstr. 1590 (2012). 
138. Chang B. Y et al. Use of tumor genomic profiling to reveal mechanisms of resistance to the BTK inhibitor ibrutinib in chronic lymphocytic leukemia (CLL). J Clin. Oncol. 31 428S (2013).

139. Rahal, R. et al. Pharmacological and genomic profiling identifies NF-kB-targeted treatment strategies for mantle cell lymphoma. Nature Med. 20, 87-92 (2014).

140. Wilson, W., Gerecitano, J., Goy, A. \& De Vos, S. The bruton's tyrosine kinase (BTK) inhibitor, ibrutinib ( $\mathrm{PCl}$-32765), has preferential activity in the abc subtype of relapsed/refractory de novo diffuse large b-cell lymphoma (DLBCL): interim results of a multicenter, open-label, phase 2 study. Proc ASH Abstr. 686 (2012).

141. Treon, S. P. A prospective, multicenter, phase II study of the Bruton's tyrosine kinase inhibitor ibrutinib in patients with relapsed and refractory Waldenstrom's macroglobulinemia. ICML Abstr. 067 (2013).

142. Vij, R., Chang, B., Berdeja, J. \& Huff, C. Early changes in cytokines, chemokines and indices of bone metabolism in a phase 2 study of the bruton tyrosine kinase (Btk) inhibitor, ibrutinib ( $\mathrm{PCl}-32765$ ) in patients with relapsed or relapsed/refractory multiple myeloma (MM). Proc ASH Abstr.4039 (2012).

143. Yan, Q. et al. BCR and TLR signaling pathways are recurrently targeted by genetic changes in splenic marginal zone lymphomas. Haematologica 97 595-598 (2012).

144. Sachen, K. L. et al. Self-antigen recognition by follicular lymphoma B-cell receptors. Blood 120 , 4182-4190 (2012)

145. Dias, C. \& Isenberg, D. A. Susceptibility of patients with rheumatic diseases to B-cell non-Hodgkin lymphoma. Nature Rev. Rheumatol. 7, 360-368 (2011).

146. Di Paolo, J. A. et al. Specific Btk inhibition suppresses B cell- and myeloid cell-mediated arthritis. Nature Chem. Biol. 7, 41-50 (2011)

147. Liu, L. et al. Antiarthritis effect of a novel Bruton's tyrosine kinase (BTK) inhibitor in rat collagen-induced arthritis and mechanism-based pharmacokinetic/ pharmacodynamic modeling: relationships between inhibition of BTK phosphorylation and efficacy. J. Pharmacol. Exp. Ther. 338, 154-163 (2011).
148. Mina-Osorio, P. et al. Suppression of glomerulonephritis in lupus-prone NZB x NZW mice by RN486, a selective inhibitor of Bruton's tyrosine Kinase. Arthritis Rheum. 65, 2380-2391 (2013).

149. Rankin, A. L. et al. Selective inhibition of BTK prevents murine lupus and antibody-mediated glomerulonephritis. J. Immunol. 191, 4540-4550 (2013)

150. Eifert, C. et al. A novel isoform of the B cell tyrosine kinase BTK protects breast cancer cells from apoptosis Genes Chromosomes Cancer 52, 961-975 (2013).

151. Mathews Griner, L. A. et al. High-throughput combinatorial screening identifies drugs that cooperate with ibrutinib to kill activated B-cell-like diffuse large B-cell lymphoma cells. Proc. Natl Acad. Sci. USA 111, 2349-2354 (2014).

152. Winkelstein, J. A. et al. X-linked agammaglobulinemia: report on a United States registry of 201 patients. Medicine 85, 193-202 (2006).

153. Nomura, K. et al. Genetic defect in human X-linked agammaglobulinemia impedes a maturational evolution of pro-B cells into a later stage of pre-B cells in the B-cell differentiation pathway. Blood 96 610-617 (2000).

154. Ng, Y. S., Wardemann, H., Chelnis, J., Cunningham-Rundles, C. \& Meffre, E. Bruton's tyrosine kinase is essential for human B cell tolerance. J. Exp. Med. 200, 927-934 (2004).

155. Hendriks, R. W. et al. Inactivation of Btk by insertion of lacZ reveals defects in $B$ cell development only past the pre-B cell stage. EMBO J. 15, 4862-4872 (1996).

156. Middendorp, S., Dingjan, G. M. ¿ Hendriks, R. W. Impaired precursor B cell differentiation in Bruton's tyrosine kinase-deficient mice. J. Immunol. 168 2695-2703 (2002)

157. Boucheron, N. \& Ellmeier, W. The role of Tec family kinases in the regulation of T-helper-cell differentiation. Int. Rev. Immunol. 31, 133-154 (2012).

158. Huck, K. et al. Girls homozygous for an IL-2-inducible $T$ cell kinase mutation that leads to protein deficiency develop fatal EBV-associated lymphoproliferation. J. Clin. Invest. 119, 1350-1358 (2009).

159. Ellmeier, W. et al. Severe B cell deficiency in mice lacking the tec kinase family members Tec and Btk J. Exp. Med. 192, 1611-1624 (2000).
160. Cenni, B., Gutmann, S. \& Gottar-Guillier, M. BMX and its role in inflammation, cardiovascular disease, and cancer. Int. Rev. Immunol. 31, 166-173 (2012).

161. He, Y. et al. Critical function of Bmx/Etk in ischemiamediated arteriogenesis and angiogenesis. J. Clin. Invest. 116, 2344-2355 (2006).

162. Dubovsky, J. A. et al. Ibrutinib is an irreversible molecular inhibitor of ITK driving a TH1 selective pressure in T-lymphocytes. Blood 122, 2539-2549 (2013).

163. Evans, E. K. et al. Inhibition of Btk with CC-292 provides early pharmacodynamic assessment of activity in mice and humans. J. Pharmacol. Exp. Ther. 346, 219-228 (2013).

164. Xu, D. et al. RN486, a selective Bruton's tyrosine kinase inhibitor, abrogates immune hypersensitivity responses and arthritis in rodents. J. Pharmacol. Exp. Ther. 341, 90-103 (2012).

165. Liu, L. et al. Significant species difference in amide hydrolysis of GDC-0834, a novel potent and selective Bruton's tyrosine kinase inhibitor. Drug Metab. Dispos. 39, 1840-1849 (2011).

166. Yoshizawa, T. Development of a Bruton's tyrosine kinase (Btk) inhibitor, ONO-4059: efficacy in a collagen induced arthritis $(\mathrm{ClA})$ model. indicates potential treatment for rheumatoid arthritis (RA). Arthritis Rheum. 64 (Suppl. 10), $1660(2012)$

167. Labenski, M. T. et al. In vitroreactivity assessment of covalent drugs targeting Bruton's tyrosine kinase. 17th North Am. Meet. Int. Soc. Study Xenobiot. (ISSX) Abst. P211 (2011).

\section{Acknowledgements}

Part of these studies were supported by the Association for International Cancer Research (to R.W.H.; 10-562) and the Dutch Arthritis Foundation (9-01-302)

Competing interests statement

The authors declare no competing interests.

DATABASES

BTKbase mutation registry: http://bioinf.uta.fi/BTKbase

ALL LINKS ARE ACTIVE IN THE ONLINE PDF 